\title{
The Emerging Role of Non-Coding RNAs in Osteoarthritis
}

\author{
Soudeh Ghafouri-Fard ${ }^{1}$, Christophe Poulet ${ }^{2,3,4}$, Michel Malaise ${ }^{2,3,4}$, Atefe Abak ${ }^{5}$, \\ Bashdar Mahmud Hussen ${ }^{6,7}$, Afshin Taheriazam ${ }^{8}$, Mohammad Taheri ${ }^{\text {* }}$ \\ and Mohammad Hallajnejad ${ }^{10 *}$
}

\begin{abstract}
${ }^{1}$ Department of Medical Genetics, School of Medicine, Shahid Beheshti University of Medical Sciences, Tehran, Iran, ${ }^{2}$ Department of Rheumatology, University Hospital of Liège (CHULiege), Liège, Belgium, ${ }^{3}$ Fibropôle Research Group, University Hospital of Liège (CHULiege), Liège, Belgium, ${ }^{4}$ GIGA-I3 Research Group, GIGA Institute, University of Liège (ULiege) and University Hospital of Liège (CHULiege), Liège, Belgium, ${ }^{5}$ Men's Health and Reproductive Health Research Center, Shahid Beheshti University of Medical Sciences, Tehran, Iran, ${ }^{6}$ Department of Pharmacognosy, College of Pharmacy, Hawler Medical University, Erbil, Iraq, ${ }^{7}$ Center of Research and Strategic Studies, Lebanese French University, Erbil, Iraq, ${ }^{8}$ Department of Orthopedics, Tehran Medical Sciences Branch, Islamic Azad University, Tehran, Iran, 9 Institute of Human Genetics, Jena University Hospital, Jena, Germany, ${ }^{10}$ Skull Base Research Center, Loghman Hakim Hospital, Shahid Beheshti University of Medical Sciences, Tehran, Iran
\end{abstract}

OPEN ACCESS

Edited by:

Steven O'Reilly,

STipe Therapeutics, Denmark

Reviewed by:

Andreia Machado Da Silva, AstraZeneca, Sweden

Hanna Taipaleenmäki, Ludwig Maximilian University of Munich, Germany

*Correspondence: Mohammad Taheri mohammad_823@yahoo.com Mohammad Hallajnejad hallajnejad@gmail.com

Specialty section: This article was submitted to Autoimmune and Autoinflammatory Disorders, a section of the journal

Frontiers in Immunology

Received: 09 September 2021 Accepted: 10 November 2021 Published: 29 November 2021

Citation:

Ghafouri-Fard S, Poulet C, Malaise M, Abak A, Mahmud Hussen B, Taheriazam A, Taheri M and Hallajnejad $M$ (2021) The Emerging Role of Non-Coding RNAs in Osteoarthritis.

Front. Immunol. 12:773171. doi: 10.3389/fimmu.2021.773171
Osteoarthritis (OS) is the most frequent degenerative condition in the joints, disabling many adults. Several abnormalities in the articular cartilage, subchondral bone, synovial tissue, and meniscus have been detected in the course of OA. Destruction of articular cartilage, the formation of osteophytes, subchondral sclerosis, and hyperplasia of synovial tissue are hallmarks of OA. More recently, several investigations have underscored the regulatory roles of non-coding RNAs (ncRNAs) in OA development. Different classes of non-coding RNAs, including long ncRNAs (IncRNAs), microRNAs (miRNAs), and circular RNAs (circRNAs), have been reported to affect the development of OA. The expression level of these transcripts has also been used as diagnostic tools in OA. In the present article, we aimed at reporting the role of these transcripts in this process. We need to give a specific angle on the pathology to provide meaningful thoughts on it.

Keywords: IncRNA, miRNA, osteoarthritis, ncRNAs, expression, circRNA

\section{INTRODUCTION}

As the most frequent degenerative condition in the joints, osteoarthritis (OA) has been associated with adults' pain and disability. Joint damage, overweight, aging, and heredity factors are regarded as an etiologic factor for OA (1). Several abnormalities in the articular cartilage, subchondral bone, synovial tissue, and meniscus have been detected in the course of OA. Destruction of articular cartilage, the formation of osteophytes, subchondral sclerosis, and hyperplasia of synovial tissue are hallmarks of OA (1). Several molecules and pathways such as TGF- $\beta$, Wnt3a, Hedgehog, Smad3, $\beta$ catenin, and HIF- $2 \alpha$ have been identified to contribute to the pathologic event during the OA course (1). In addition, systemic inflammation and the secreted cytokines in this process, particularly IL- $1 \beta$ and TNF- $\alpha$ can activate the NF- $\kappa B$ pathway in synovial cells and chondrocytes, participating in the pathogenesis of OA $(1,2)$. More recently, several investigations have underscored the regulatory roles of non-coding RNAs (ncRNAs) in OA development. Different classes of non-coding RNAs, including long ncRNAs (lncRNAs), microRNAs (miRNAs), and circular RNAs (circRNAs), have been reported to affect the 
development of OA. In the present article, we aimed at reporting the role of these transcripts in this process.

\section{LncRNAs IN OSTEOARTHRITIS}

LncRNAs are transcripts with sizes of more than 200 nucleotides. Although they are not translated into functional polypeptides, they have crucial functions in regulating protein-coding genes' expression. As a novel epigenetic control level, they affect several human disorders' pathogenic course (3). Despite poor evolutionary conservation across different species (4) and a low level of expression in many tissues $(5,6)$, their functionality in the regulation of gene expression in cis- and trans- modes has been verified (3). These transcripts can serve as molecular sponges for miRNAs to release miRNA targets from inhibitory effects of miRNAs. Moreover, they can induce the H3K27 trimethylation, as a repressive epigenetic mark in the promoter of certain genes, thus inactivating target genes (7).

In the course of OA, several lncRNAs have been reported to be dysregulated. Function of some of lncRNAs in the pathogenesis of osteoarthritis has been described with more details in research papers. In this section, we selected some of them with clearer mechanistical information. For instance, expression of $\mathrm{H} 19$ has been reported to be up-regulated in samples from OA patients and chondrocytes cultured in the presence of IL-1 $\beta$ (8). H19 up-regulation has suppressed proliferation and stimulated apoptosis in these chondrocytes, whereas $\mathrm{H} 19$ silencing has exerted the opposite impact. These effects are mediated through sponging miR-106a-5p (8). Notably, expression of this IncRNA has also been shown to be elevated in peripheral blood of patients with OA in correlation with the Kellgren and Lawrence (K-L) grading system. Besides, its expression has been inversely correlated with bone metabolism parameters, namely PINP, N-MID, BGP, BALP, and Lysholm score, while being positively correlated with $\beta$-CTX parameter and VAS and WOMAC scores (9). In addition to H19, expression of HOTAIR has been up-regulated in cartilage samples of the femoral condyles or tibial plateaus of patients affected with OA compared with control samples. Up-regulation of this lncRNA has led to a severe upsurge of apoptotic rate and decreased chondrocyte viability. Mechanistically, HOTAIR increases Bax expression and the proteolytic cleavage of caspase 3 and decreases survivin and Bcl-2 levels. In chondrocytes, functional studies have shown that HOTAIR acts as a sponge for miR-130a-3p, i.e. sequesters this miRNA and releases its targets from inhibitory effects of this miRNA (10). Another functional route for the participation of HOTAIR in the development of $\mathrm{OA}$ is through enhancement of expression of genes related to cartilage destruction. HOTAIR directly represses the expression of Wnt inhibitory factor 1 (WIF-1) through induction of $\mathrm{H} 3 \mathrm{~K} 27$ trimethylation in its promoter, thus activating the Wnt/ $\beta$-catenin pathway (7). DANCR is another up-regulated lncRNA in human OA cartilage and lipopolysaccharide (LPS)-induced chondrocyte cells. DANCR silencing has attenuated LPS-associated apoptosis and inflammation, enhanced cell survival, abridged apoptosis, and reduced IL-1 $\beta$, IL-6, IL-8, and TNF- $\alpha$ levels. DANCR functions are mediated via sponging miR-19a (11). In addition, DANCR has been recently found to regulate expression of SOX9 (12). DANCR has also been shown to enhance the proliferation of synovial fluid-derived mesenchymal stem cells and increase chondrogenesis through sponging miR-1275, a miRNA that regulates the expression of MMP13 and regulate its expression. Through similar route, DANCR regulates expression of SOX9 (13). Expression of MALAT1 has also been elevated in the synovial tissues of obese OA patients compared with normalweight OA cases or non-OA controls. Its expression has been sharply activated following the induction of OA synovial fibroblasts with pro-inflammatory cytokines. MALAT1 silencing has reduced levels of CXCL8 in OA synovial fibroblasts while increasing TRIM6, IL7R, HIST1H1C, and MAML3 levels. Moreover, MALAT1 silencing has suppressed the proliferation of synovial fibroblasts of obese OA patients (14). NEAT1 and XIST are among other lncRNAs whose contribution to the pathogenesis of $\mathrm{OA}$ has been vastly investigated. Nevertheless, the results of the studies of their expression patterns are not consistent. In this section, we summarize studies that reported their up-regulation in OA. NEAT1 was described as a regulator of the OA development through sponging miR-193a-3p, miR-543, and miR-377-3p, thus increasing expressions of SOX5 and PLA2G4A. Subsequently, it affects chondrocyte proliferation and apoptosis and extracellular matrix (ECM) degradation (15-17). XIST increases OPN levels while decreasing miR-1277-5p, miR-142-5p and TIMP-3 levels. Changes in these genes' expression result in ECM destruction, induction of inflammatory responses, and abnormal proliferation/apoptosis of chondrocytes (18-21). Table 1 shows the results of studies that demonstrated up-regulation of lncRNAs in OA tissues.

While most of the studies which assessed the expression of NEAT1 or XIST in OA samples reported their up-regulation, few studies have demonstrated the opposite trend in their expressions. Lian et al. have reported down-regulation of XIST in OA chondrocytes. They have also shown protective effects of XIST in chondrocytes against IL-1 $\beta$-induced damage through modulating the miR-653-5p/SIRT1 axis (42). Wang et al. have demonstrated down-regulation of NEAT1 in OA tissues, parallel with up-regulation of miR-181a. They have also shown that down-regulation of NEAT1 suppresses cell growth, elevates apoptosis, and increases the production of pro-inflammatory cytokines in OA chondrocytes (43). SNHG7 is another downregulated $\operatorname{lncRNA}$ in OA. This lncRNA sponges miR-34a-5p and miR-214-5p $(44,45)$. Due to its sponging effects on miR-34a-5p, down-regulation of SNHG7 results in down-regulation of SYVN1, the direct target of this miRNA. Up-regulation of SNHG7 enhances cell proliferation and suppresses apoptosis and autophagy in OA cells (44). Also, SNHG7 can enhance cell viability and inhibit apoptosis and inflammatory responses in IL-1 $\beta$-mediated chondrocytes through sponging miR-214-5p and up-regulating PPARGC1B expression. Thus, the protective effects of SNHG7 against OA are exerted through induction of 
TABLE 1 | Up-regulated IncRNAs in OA.

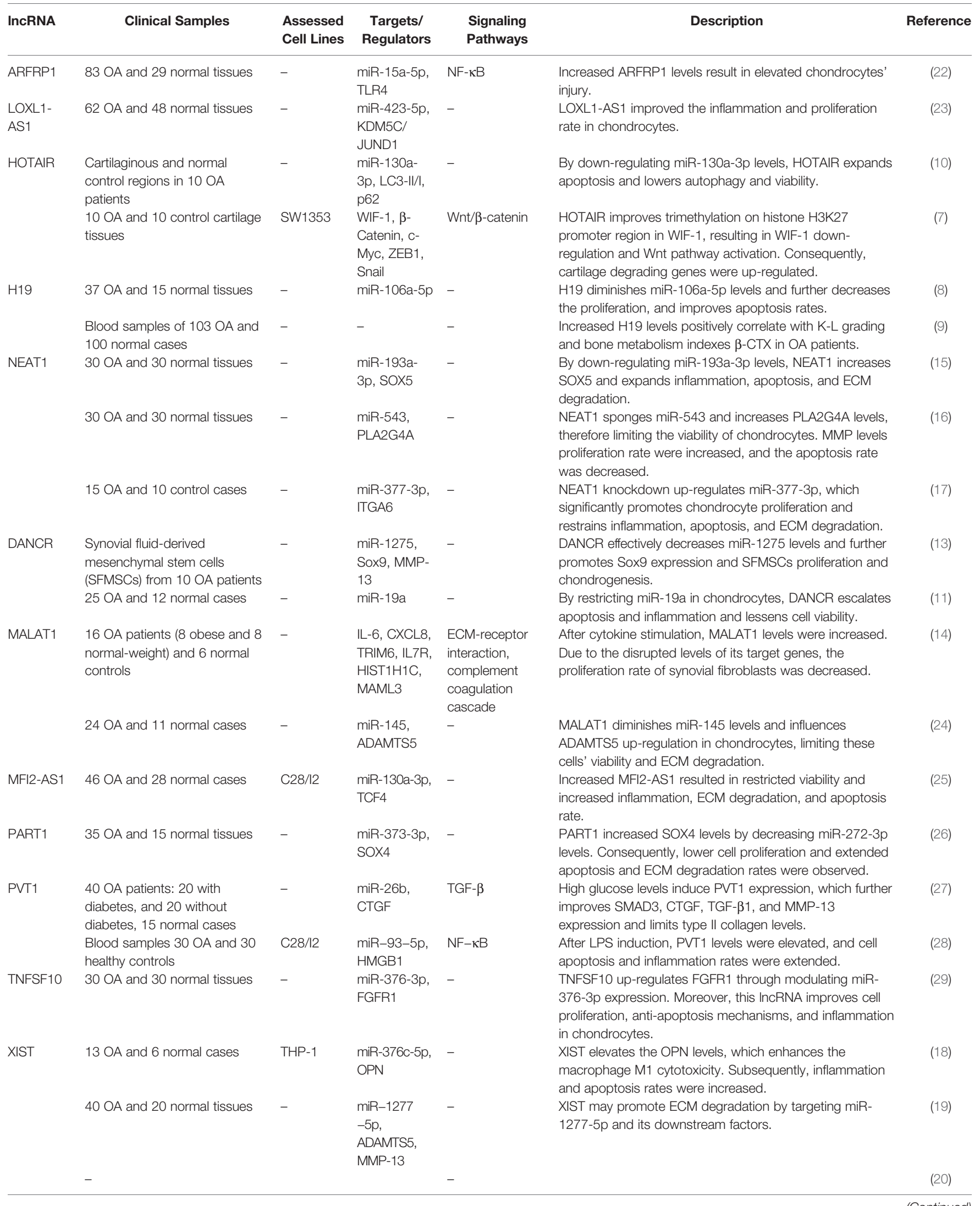


TABLE 1 | Continued

\begin{tabular}{|c|c|c|c|c|c|c|}
\hline IncRNA & Clinical Samples & $\begin{array}{l}\text { Assessed } \\
\text { Cell Lines }\end{array}$ & $\begin{array}{c}\text { Targets/ } \\
\text { Regulators }\end{array}$ & $\begin{array}{l}\text { Signaling } \\
\text { Pathways }\end{array}$ & Description & Reference \\
\hline & & $\begin{array}{l}\text { SW1353, } \\
\text { HEK293T }\end{array}$ & $\begin{array}{l}\text { miR-142-5p, } \\
\text { SGTB }\end{array}$ & & $\begin{array}{l}\text { XIST knockdown leads to miR-142-5p up-regulation, } \\
\text { increased proliferation, and ECM synthesis. }\end{array}$ & \\
\hline & $15 \mathrm{OA}$ and 7 normal tissues & - & TIMP-3 & - & $\begin{array}{l}\text { XIST binds to the TIMP-3 promoter and increases its } \\
\text { methylation. Subsequently, in OA cases, increased } \\
\text { collagen destruction was observed. }\end{array}$ & $(21)$ \\
\hline $\mathrm{CHRF}$ & - & ATDC5 & $\begin{array}{l}\operatorname{miR}-146 a \\
\text { IкB } \alpha, p 65 \\
\text { JAK1, } \\
\text { STAT3/IL-6 }\end{array}$ & 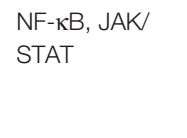 & $\begin{array}{l}\text { CHRF increases apoptosis and inflammatory damages by } \\
\text { inducing IL- } 6 \text { expression. }\end{array}$ & (30) \\
\hline CASC2 & $\begin{array}{l}\text { Blood samples from } 71 \text { OA and } \\
55 \text { healthy controls, synovial } \\
\text { fluid samples from } 21 \text { OA and } \\
15 \text { healthy controls }\end{array}$ & $\begin{array}{l}\mathrm{CHON}- \\
001\end{array}$ & $\| \mathrm{L}-17$ & - & $\begin{array}{l}\text { Increased CASC2 in chondrocytes results in elevated IL- } \\
17 \text { levels and restricted proliferation. }\end{array}$ & (31) \\
\hline $\begin{array}{l}\text { FOXD2- } \\
\text { AS1 }\end{array}$ & $35 \mathrm{OA}$ and 35 normal cases & $\mathrm{C} 28 / 12$ & $\begin{array}{l}\operatorname{miR}-27 a-3 p \\
\text { TLR4/IL-1 } \\
\text { TNF-a }\end{array}$ & - & $\begin{array}{l}\text { FOXD2-AS1 improves inflammation and ECM degradation } \\
\text { in cells by down-regulating miR-27a-3p. }\end{array}$ & $(32)$ \\
\hline $\mathrm{H} 19$ & - & $\begin{array}{l}\text { C28/I2, } \\
\text { HEK293T }\end{array}$ & miR-130a & - & $\begin{array}{l}\text { After LPS induction, H19 levels, inflammatory factors, and } \\
\text { apoptosis rate were increased. }\end{array}$ & (33) \\
\hline TM1P3 & $35 \mathrm{OA}$ and 10 normal cases & - & $\begin{array}{l}\text { miR-22, } \\
\text { SMAD1/5, } \\
\text { MMP13, } \\
\text { ALK1/IL-1 }\end{array}$ & TGF- $\beta$ & $\begin{array}{l}\text { TIMP3, up-regulated by IL-1, diminishes miR- } 22 \text { levels, } \\
\text { and by affecting the TGF- } \beta \text { pathway, the ECM degradation } \\
\text { rate was increased. }\end{array}$ & (34) \\
\hline THRIL & - & ATDC5 & $\begin{array}{l}\text { miR-125b, } \\
\text { JAK1, STAT3 }\end{array}$ & $\begin{array}{l}\text { JAK/STAT, NF- } \\
\kappa B\end{array}$ & $\begin{array}{l}\text { Up-regulation of THRIL intensified the LPS-induced } \\
\text { inflammatory injury and apoptosis. }\end{array}$ & (35) \\
\hline SNHG16 & $20 \mathrm{OA}$ and 20 normal tissues & $\begin{array}{l}\mathrm{CHON} \\
-001\end{array}$ & $\begin{array}{l}\operatorname{miR}-373 \\
-3 p, p 21\end{array}$ & - & $\begin{array}{l}\text { SNHG16 decreases miR-373-3p and increases p21 levels, } \\
\text { which further limits the viability and proliferation of cells. } \\
\text { Collagen II and aggrecan levels were also reduced. }\end{array}$ & (36) \\
\hline$|\mathrm{GHC} \gamma|$ & $\begin{array}{l}\text { Blood samples of } 88 \text { cases and } \\
36 \text { healthy controls }\end{array}$ & THP-1 & $\begin{array}{l}\text { miR-6891- } \\
\text { 3p, TLR4 }\end{array}$ & $N F-\kappa B$ & $\begin{array}{l}\text { IGHC } \gamma 1 \text { increased TLR4 expression through limiting miR- } \\
6891-3 p \text {, and improved macrophage proliferation, } \\
\text { migration, and inflammatory responses. }\end{array}$ & $(37)$ \\
\hline $\begin{array}{l}\text { CTBP1- } \\
\text { AS2 }\end{array}$ & $62 \mathrm{OA}$ and 62 healthy controls & - & miR-130a & - & $\begin{array}{l}\text { CTBP1-AS2 methylates and deactivates miR-130a } \\
\text { expression, which limits the proliferation rate. }\end{array}$ & $(38)$ \\
\hline LINC00511 & 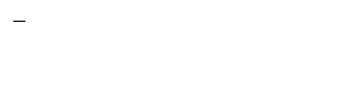 & ATDC5 & $\begin{array}{l}\text { miR-150-5p, } \\
\text { SP1 }\end{array}$ & - & $\begin{array}{l}\text { LINC00511 down-regulation leads to expanded } \\
\text { proliferation rate and ECM synthesis. By inducing a } \\
\text { positive feedback loop, SP1 increases LINC00511 levels. }\end{array}$ & (39) \\
\hline GAS5 & $\begin{array}{l}\text { Blood samples of } 35 \mathrm{OA} \text { and } \\
35 \text { control cases }\end{array}$ & - & $\mathrm{miR}-137$ & - & $\begin{array}{l}\text { By reducing miR-137 levels, GAS5 limits the proliferation } \\
\text { rate of chondrocytes. }\end{array}$ & $(40)$ \\
\hline LINC00461 & $\begin{array}{l}25 \mathrm{OA} \text { and } 15 \text { control cartilage } \\
\text { tissues }\end{array}$ & - & miR-30a-5p & - & $\begin{array}{l}\text { IL-6 and TNF- } \alpha \text { promote LINC00461 expression, restrict } \\
\text { miR-30a-5p levels, and further improved cell cycle } \\
\text { progression, chondrocyte proliferation, inflammation, and } \\
\text { ECM degradation. }\end{array}$ & $(41)$ \\
\hline
\end{tabular}

the PPAR $\gamma$ pathway and combating the cytotoxic impact of miR214-5p (45). The protective effects of other lncRNAs against OA are summarized in Table 2.

\section{miRNAs IN OSTEOARTHRITIS}

miRNAs are the utmost investigated small ncRNAs, representing an additional level of post-transcriptional controllers of gene expression that warrant the robustness of coordination in biological processes (67). These transcripts typically bind with the 3' UTR of their target transcripts to either repress their translation or degrade them (68). In this section, we selected some miRNAs with clearer mechanistical information. Cheng et al. have reported up-regulation of miR-455-3p in the OA cartilages and IL-1 $\beta$-exposed chondrocyte cells. This miRNA has been shown to partake in IL-1 $\beta$-associated apoptosis and inflammatory responses. COL2A1 has been verified as a target of miR-455-3p designating the miR-455-3p/COL2A1 axis as a molecular mediator of OA (69). While confirming the role of miR-455-3p in OA's chondrogenesis and development, Wen et al. have demonstrated down-regulation of this miRNA in the IL-1 $\beta$ model of OA. Over-expression of miR-455-3p has led to a significant decrease in PTEN and MMP13 while increases the COL2A1 expression levels. Moreover, based on their observations, miR-455-3p can decrease chondrocytes' apoptotic rate by affecting PTEN expression (70). Despite using similar OA models, these studies have reported conflicting results regarding the role of miR-455-3p in the development of OA. Wand et al. have demonstrated up-regulation of miR-1236 in OA-affected cartilages compared to normal cartilages. Such up-regulation has inhibited chondrocyte proliferation and induced apoptosis in these cells through targeting PIK3R3 (71). miR-411 is another up-regulated miRNA in OA models. This miRNA directly affects 
TABLE 2 | Down-regulated IncRNAs in OA.

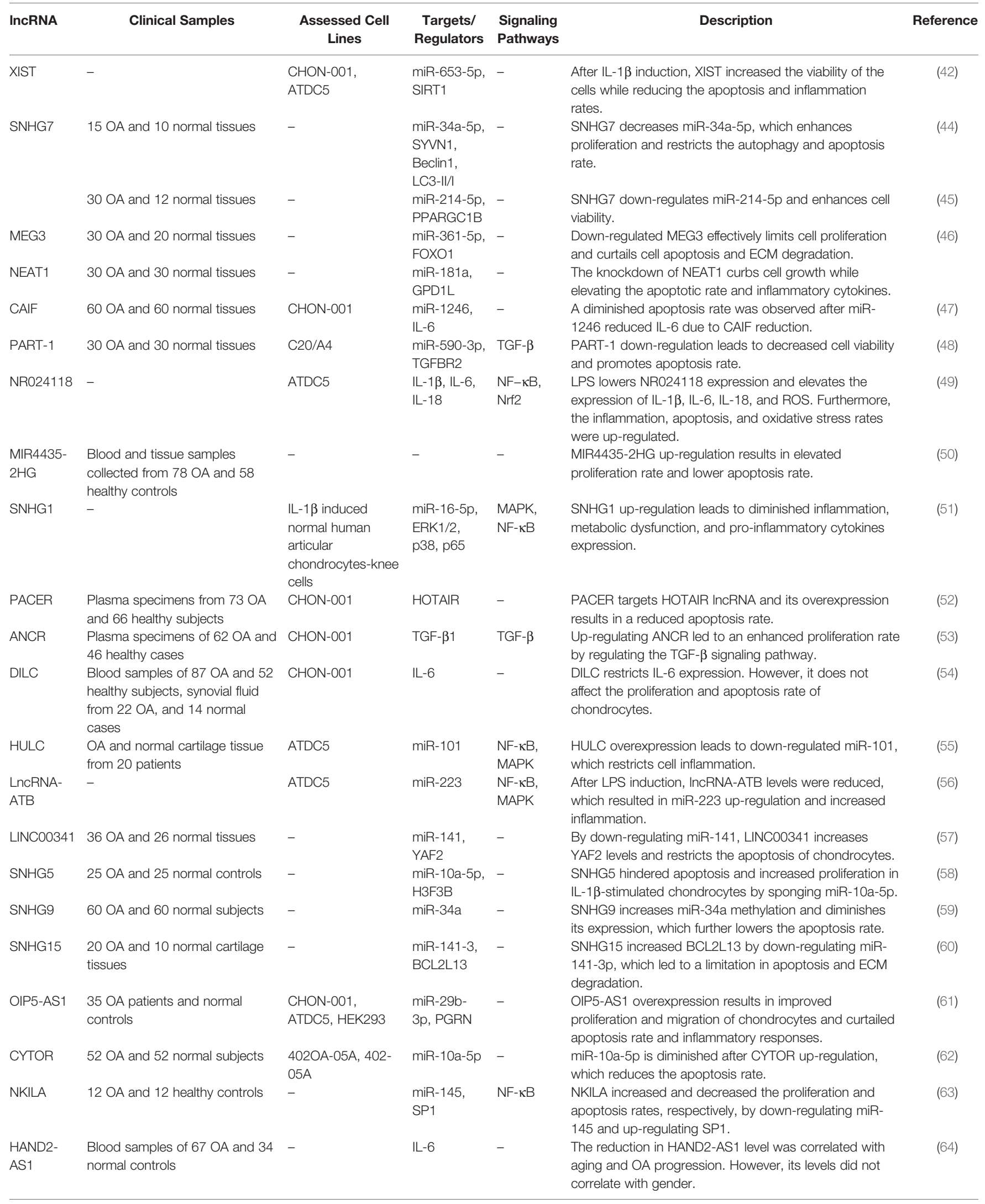


TABLE 2 | Continued

\begin{tabular}{|c|c|c|c|c|c|c|}
\hline IncRNA & Clinical Samples & $\begin{array}{c}\text { Assessed Cell } \\
\text { Lines }\end{array}$ & $\begin{array}{c}\text { Targets/ } \\
\text { Regulators }\end{array}$ & $\begin{array}{l}\text { Signaling } \\
\text { Pathways }\end{array}$ & Description & Reference \\
\hline LINC00623 & $\begin{array}{l}\text { Chondrocyte isolation from } \\
\text { normal and OA affected cartilage } \\
\text { tissues }\end{array}$ & - & $\begin{array}{l}\text { miR-101, } \\
\text { HRAS }\end{array}$ & MAPK & $\begin{array}{l}\text { LINC00623 increases HRAS levels by down-regulating } \\
\text { miR-101, which leads to lower ECM degradation and } \\
\text { apoptosis rates. }\end{array}$ & (65) \\
\hline LUADT1 & $60 \mathrm{OA}$ and 60 healthy cases & - & $\begin{array}{l}\text { miR-34a, } \\
\text { SIRT1 }\end{array}$ & - & $\begin{array}{l}\text { LUADT1 down-regulation leads to miR-34a up-regulation } \\
\text { and SIRT1 reduction. SIRT1, accordingly, increased the } \\
\text { apoptosis rate of chondrocytes. }\end{array}$ & (66) \\
\hline
\end{tabular}

the expression of HIF-1 $\alpha$. LC3, ULK-1, P62, and Beclin-1 have been among genes whose expressions have been affected by miR411. miR-411 has been shown to enhance chondrocyte autophagy through modulating HIF- $1 \alpha$ (72). miR-203 is another miRNA whose expression has been promoted by IL-1 $\beta$ stimulation. This miRNA enhances cellular inflammatory responses and cell damage and reduced aggrecan and Col2A1 levels. miR-203 binds with $\mathrm{ER} \alpha$ and exerts its effects in OA development through this axis (73). miR-140 and miR-199 are two down-regulated miRNAs in the synovial tissues of OA patients compared with healthy controls. Expressions of these miRNAs have been shown to decrease during the course of OA. Moreover, their expressions have been inversely correlated with the severity of OA (74). The course of OA has been found to be alleviated by exosomal miR-9-5p produced by mesenchymal stem cells originated from bone marrow. This miRNA has been shown to decrease syndecan-1 levels and diminish pro-inflammatory cytokines as well as CRP (75). Tables 3 and 4 show the up-regulated and down-regulated miRNAs in $\mathrm{OA}$, respectively.

\section{CircRNAs IN OSTEOARTHRITIS}

These ncRNAs have a circular conformation shaped by routine spliceosome-mediated or lariat kind of splicing (85). Exonic circRNAs, circular intronic RNAs, exonic-intronic circRNAs, and tRNA intronic circRNAs constitute the main classes of
circRNAs (85). Circ_0136474 is a member of this group which can inhibit cell proliferation by enhancing MMP-13 expression and decreasing miR-127-5p levels in OA (86). Hsa_circ_0005105 is another up-regulated circRNA in IL- $1 \beta$-induced chondrocytes. Hsa_circ_0005105 has been shown to suppress transcriptional activity of miR-26a, thus up-regulating expression of NAMPT, the direct target of this miRNA. Moreover, hsa_circ_0005105 can decrease the levels of type II collagen and aggrecan, enhance MMP-13 and ADAMTS-4 levels, and increase the production of PGE2, IL-6, and IL-8 (87). CircHIPK3 is another circRNA that regulates the apoptosis rate of chondrocytes through the miR124/SOX8 axis (88). On the other hand, circRNA-UBE2G1 mainly regulates $\mathrm{OA}$ development through influencing inflammatory responses. This circRNA targets miR-373 and increases IL-1 $\beta$, IL- 6 , and TNF- $\alpha$ levels in LPS-treated cells (89). Tables 5 and $\mathbf{6}$ show the list of up-regulated and downregulated circRNAs in OA, respectively.

\section{ANIMAL STUDIES}

In addition to cell line studies and expression assays in human samples, the expression and function of ncRNAs have been appraised in OA animal models. Commonly, the observed dysregulation of ncRNAs in the animal models is consistent with findings in human-derived OA tissues and in vitro studies. Moreover, deregulation of these transcripts has similar outcomes in the animals and in in vitro studies. In fact, animal studies have

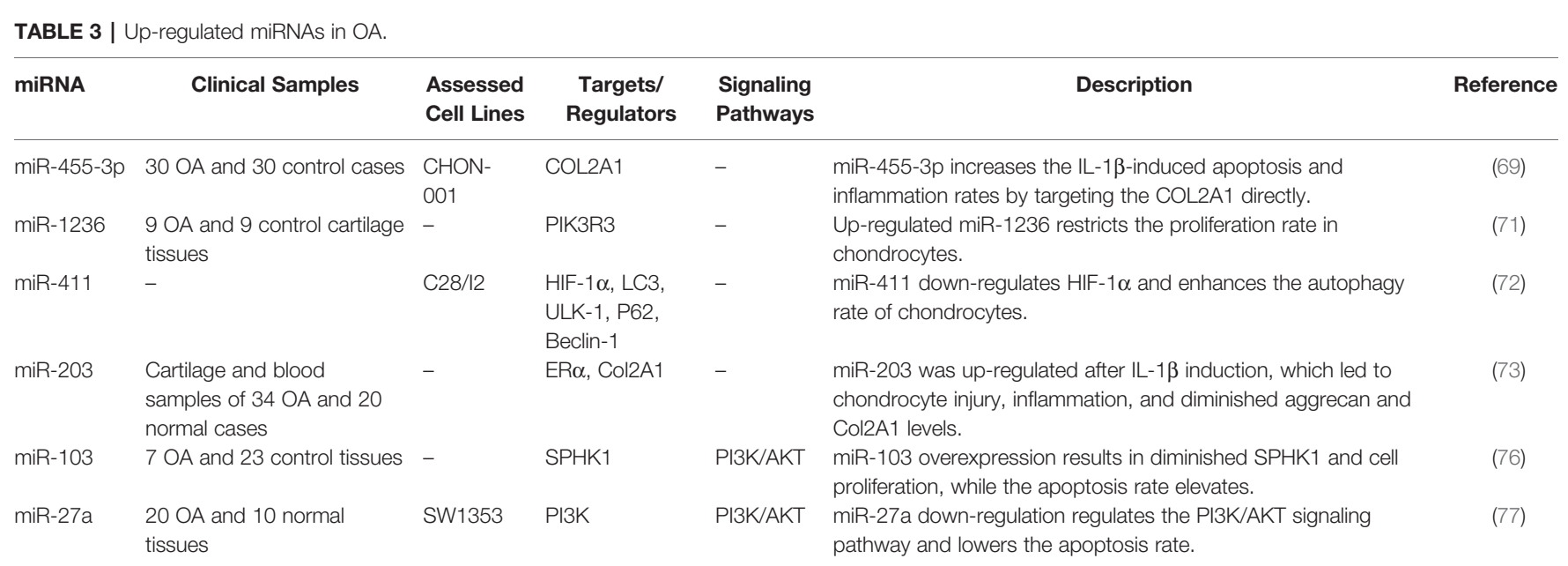


TABLE 4 | Down-regulated miRNAs in OA.

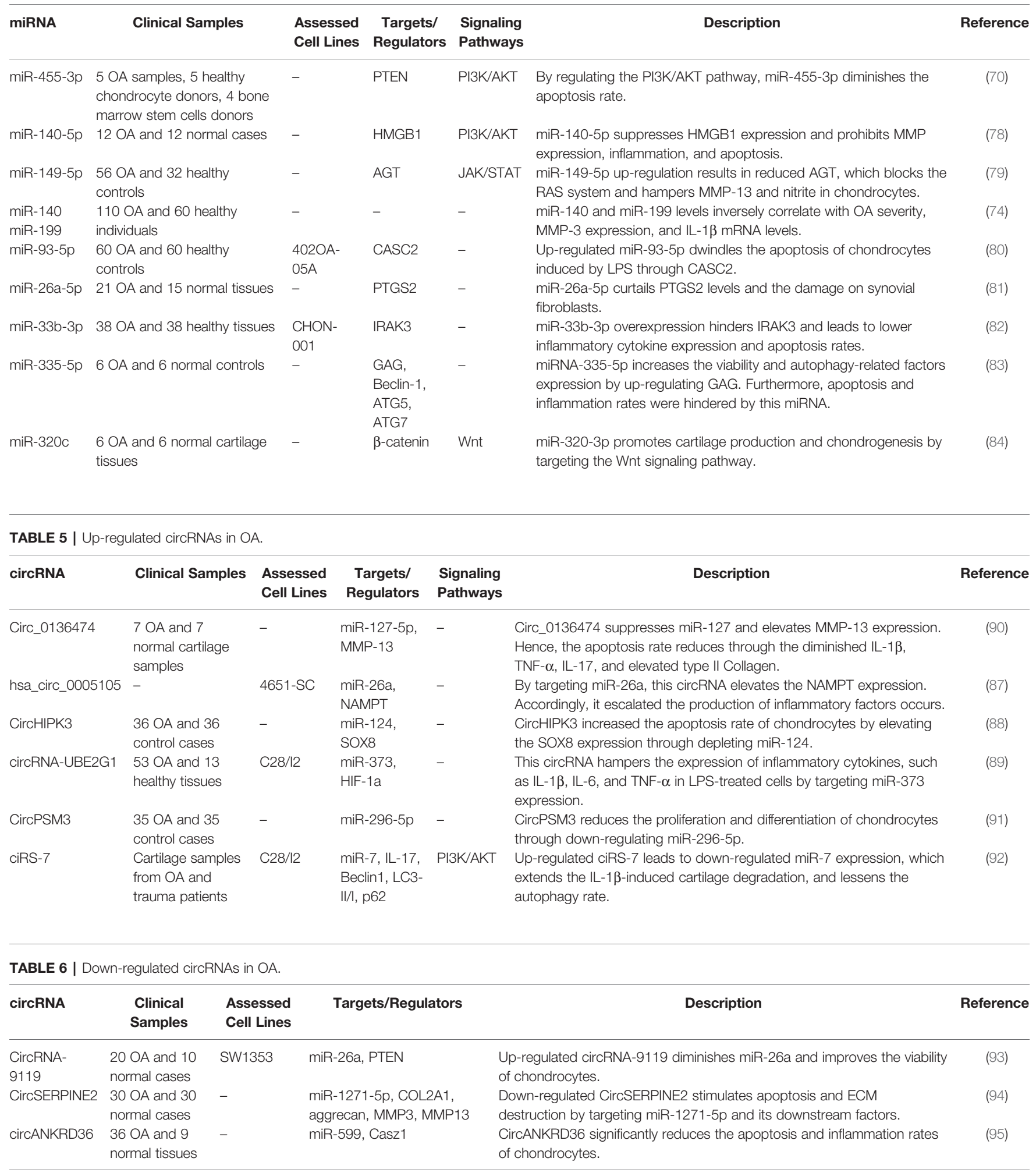

provided strong evidence for functionality of these transcripts in the pathogenesis of OA. As an example, HOTAIR has been shown to be elevated in articular cartilage samples of OA mice in association with down-regulation of miR-20b and up-regulation of PTEN. HOTAIR knockdown has ameliorated cartilage tissue injury in animal models and enhanced collagen II and aggrecan levels in this tissue while decreasing MMP-13 and ADAMTS-5 levels (96). LOC101928134 and LINC00662 are two other 
lncRNAs whose functions in OA development have been investigated in animal models (97, 98). While LOC101928134 increases apoptosis and cartilage damage through activation of the JAK/STAT signaling pathway (97), LINC00662 reduces apoptosis and inflammatory factors such as IL-6 and IL-8 (98). miR-34a, miR-363-3p, miR-101a-3p, circRNA.33186, and circRNA_Atp9b are other ncRNAs whose roles in the development of OA have been appraised in animal models (Table 7).

\section{ACTION OF nCRNAS UPON KEY PATHWAYS IN OSTEOARTHRITIS}

NcRNA can affect pathoetiology of OA through different routes such as JAK/STAT, NF- $\kappa B, P I 3 K / A K T$ and $\mathrm{Wnt} / \beta$-catenin signaling pathways as well as autophagy. It is worth mentioning that a single ncRNA might affect pathogenesis of OA through modulation of different pathways. For instance, HOTAIR has been found to affect both PI3K/AKT signaling and autophagy, thus it has a pleiotropic role in OA. In fact, these effects might be complementary to each other to worsen disease progression. Similarly, the same signaling pathway can be affected by many different ncRNAs at different points. One might deduce that these ncRNAs act in a timely-concerted manner, yet no study has assessed the effects of these ncRNAs at different regulatory points of signaling pathways or during the course of OA. Thus, there is no proof for this hypothesis based on the currently available literature.
Activation of JAK/STAT signaling pathway acts as a common connection linking pro-inflammatory cytokines to inflammation in the context of OA (104). In addition, expression of the NF- $\kappa B$ family of transcription factors can be induced by pro-inflammatory cytokines and chemokines as well as degradation products of extracellular matrix. Activation of NF- $\kappa \mathrm{B}$ molecules can increase expression of several genes which increase damage to the articular joint, thus participating in the pathogenesis of osteoarthritis (105). A number of ncRNAs can affect pathogenesis of OA via modulation of these pathways. Figure 1 illustrates the role of various ncRNAs in regulating the JAK/STAT and NF- $\mathrm{KB}$ signaling pathways in OA.

The abnormal alterations in the course of osteoarthritis mostly are linked with dysfunction of chondrocytes and autophagy, an intracellular mechanism of degradation that preserves the stable condition of cellular metabolism. This process is also regarded as a mechanism for restoring activity of injured chondrocytes. Thus, it has a role in alleviation of OA (106). Figure 2 represents the role of several ncRNAs in OA through regulating the autophagy pathway.

Wnt signaling has an important role in osteoarthritis pathogenesis and is regarded as a potential target for treatment of this disorder. Wnt pathway contains $19 \mathrm{Wnt}$ genes and several receptors regulating canonical and non-canonical pathways, the latter being dependent on $\beta$-catenin. Wnt signaling has important roles in the regulation of proliferation and differentiation of cells, as well as their polarization (107). PI3K/ $\mathrm{AKT} / \mathrm{mTOR}$ signaling pathway is another pathway which has important roles in the normal metabolic pathways in the joints

TABLE 7 | Summary of studies that reported the role of ncRNAs in animal models of OA.

\begin{tabular}{|c|c|c|c|c|c|c|}
\hline ncRNA & $\begin{array}{l}\text { Expression } \\
\text { Pattern }\end{array}$ & Animal model & $\begin{array}{l}\text { Targets/ } \\
\text { regulators }\end{array}$ & $\begin{array}{l}\text { Signaling } \\
\text { Pathway }\end{array}$ & Description & Reference \\
\hline HOTAIR & Up & $\begin{array}{l}\text { Male adult C57BL/ } 6 \text { mice, OA } \\
\text { model was induced by medial } \\
\text { collateral ligament transection } \\
\text { and DMM. }\end{array}$ & $\begin{array}{l}\text { miR-20b, } \\
\text { PTEN }\end{array}$ & PTEN & $\begin{array}{l}\text { HOTAIR expression results in diminished collagen II and } \\
\text { aggrecan and improved MMP-13 and ADAMTS-5 } \\
\text { expression. This IncRNA further declined the proliferation } \\
\text { and heightened ECM destruction. }\end{array}$ & (96) \\
\hline LOC101928134 & Up & $\begin{array}{l}\text { Sprague-Dawley rats, OA was } \\
\text { induced by anterior cruciate } \\
\text { ligament Transection. }\end{array}$ & IFNA1 & JAK/STAT & $\begin{array}{l}\text { This IncRNA elevates IFNA1 and activates JAK/STAT } \\
\text { signaling pathway. Consequently, apoptosis and cartilage } \\
\text { damage rates were increased. }\end{array}$ & $(97)$ \\
\hline LINC00662 & Down & $\begin{array}{l}\text { Male Sprague-Dawley rats, OA } \\
\text { was induced by medial capsular } \\
\text { incision. }\end{array}$ & $\begin{array}{l}\operatorname{miR}-15 b- \\
5 p \\
\text { GPR120 }\end{array}$ & - & $\begin{array}{l}\text { After LINC00662 reduction, miR-15b-5p is increased, which } \\
\text { results in reduced GRP120 levels. Consequently, apoptosis } \\
\text { and inflammatory factors such as IL- } 6 \text { and IL- } 8 \text { were } \\
\text { elevated. }\end{array}$ & (98) \\
\hline miR-34a & Up & $\begin{array}{l}\text { male Sprague Dawley rats were } \\
\text { subjected to anterior cruciate } \\
\text { ligament transection. }\end{array}$ & - & PI3K/AKT & $\begin{array}{l}\text { miR-34a decreases the proteins involved in PI3K/AKT } \\
\text { pathway and increases the apoptosis rate of chondrocytes. }\end{array}$ & (99) \\
\hline miR-363-3p & Up & $\begin{array}{l}\text { Male Wistar rats were subjected } \\
\text { to medial meniscectomy tear } \\
\text { surgery. }\end{array}$ & NRF1 & p53 & $\begin{array}{l}\text { miR-363-3p elevates the apoptosis rate by enhancing IL } \\
-1 \beta, I L-6 \text {, and TNF- } \alpha \text { expression. }\end{array}$ & $(100)$ \\
\hline miR-101a-3p & Down & $\begin{array}{l}\text { Sprague Dawley rats were } \\
\text { injected with Complete Freund's } \\
\text { Adjuvant emulsion into the } \\
\text { upper TMJ cavities. }\end{array}$ & $\begin{array}{l}\text { UBE2D1, } \\
\text { FZD4 }\end{array}$ & Wnt & $\begin{array}{l}\text { miR-101a-3p significantly improves the apoptosis of } \\
\text { chondrocytes by regulating the Wnt signaling pathway. }\end{array}$ & $(101)$ \\
\hline circRNA.33186 & Up & $\begin{array}{l}\text { Adult male C57BL/6 mice were } \\
\text { subjected to DMM surgery. }\end{array}$ & $\begin{array}{l}\text { miR-127- } \\
5 p, \text { MMP- } \\
13, \text { Col2a1 }\end{array}$ & - & $\begin{array}{l}\text { circRNA.33186 down-regulates miR-127 and up-regulates } \\
\text { MMP-13 expression, which leads to diminished cell } \\
\text { proliferation rate. }\end{array}$ & $(102)$ \\
\hline circRNA_Atp9b & Up & $\begin{array}{l}\text { Mouse articular chondrocytes } \\
\text { obtained from the knee joints }\end{array}$ & $\begin{array}{l}\text { miR-138- } \\
5 p \\
\text { MMP13, IL- } \\
6, \text { COX-2 }\end{array}$ & - & $\begin{array}{l}\text { CircRNA_Atp9b down-regulation increases collagen type II } \\
\text { and inhibits MMP13, COX-2, and IL-6 expression, resulting } \\
\text { in ECM degradation and inflammation. }\end{array}$ & (103) \\
\hline
\end{tabular}




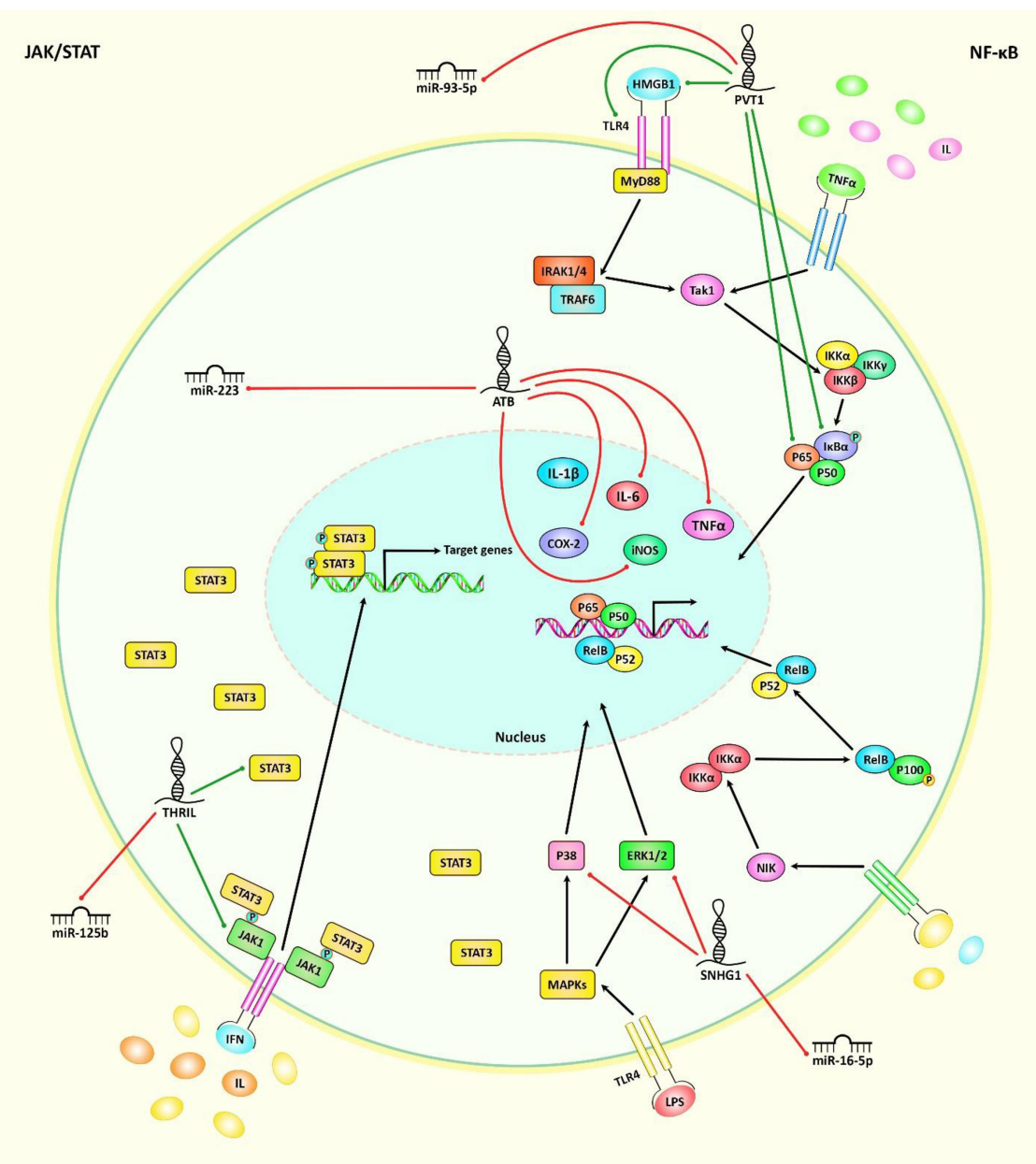

FIGURE 1 | A schematic illustration of the role of various noncoding-RNAs in modulating the JAK/STAT and NF-kB signaling pathways in osteoarthritis. Mounting studies have revealed that multiple ncRNAs (IncRNAs, circRNAs, and miRNAs) have important roles in osteoarthritis through regulating the JAK/STAT and NF-KB cascades. As an illustration, IncRNA PVT1 could play an effective role in upregulating TLR4/NF-KB signaling cascade via modulating miR-93-5p/HMGB1 axis in osteoarthritis patients, therefore inducing osteoarthritis development (28). In addition, IncRNA-ATB overexpression could have a crucial part in downregulating the expression levels of iNOS, COX-2, IL-6 and TNF- $\alpha$ proteins. These IncRNA could reduce miR-223 expression through suppressing MyD88/NF-KB and p38MAPK cascades, and thereby alleviating lipopolysaccharideinduced inflammatory injury in osteoarthritis patients (56). Another study has confirmed that IncRNA SNHG1 through downregulating the expression levels of IL-6, TNF- $\alpha$, iNOS, COX-2, ERK1/2, P38, and P65 as well as suppressing miR-16-5p-mediated p38MAPK and NF-kB signaling cascades could have an effective role in alleviating IL-1ßinduced osteoarthritis (51). Green arrows indicate the upregulation of target genes modulated via ncRNAs (IncRNAs, circRNAs, and miRNAs), red arrows depict inhibition regulated by these ncRNAs. All the information regarding the role of up-regulated or down-regulated ncRNAs in modulating osteoarthritis can be seen in Tables 1-7.

and participates in the development of $\mathrm{OA}$ through induction of cartilage degradation, impairment of function of subchondral bones, and induction of inflammatory responses in the synovial tissues (108). Figure 3 illustrates the role of different ncRNAs in $\mathrm{OA}$ through modulating the PI3K/AKT and $\mathrm{Wnt} / \beta$-catenin signaling pathways.

\section{ASSOCIATION BETWEEN ncRNAS POLYMORPHISMS AND OA}

H19, MEG3, and PRNCR1 are three lncRNAs whose polymorphisms have been associated with OA's risk. For instance, the A allele of the rs 217727 within $\mathrm{H} 19$ can enhance the risk of OA. However, the rs3741219 within this IncRNA has not affected the risk. Notably, the rs 217727 polymorphism has been associated with the levels of H19, hsa-miR-4804-5p, hsamiR-8071, hsa-miR-8072, and hsa-miR-3960 in the circulation. Besides, the A allele of the rs7158663 within MEG3 can increase the risk of OA. rs7158663 has been associated with the plasma levels of its host genes, i.e. hsa-miR-4307 and hsa-miR-1265 (109). Finally, the G allele of rs 1456315 within PRNCR1 can increase the risk of OA (110).

An integrative analysis of lncRNAs association with OA has shown that RegulomeDB scores of three SNPS within H19, MEG3 and HOTTIP have been 2b (111). Based on the ChIPseq data, these SNPs can bind with EZH2, E2F6, REST and 


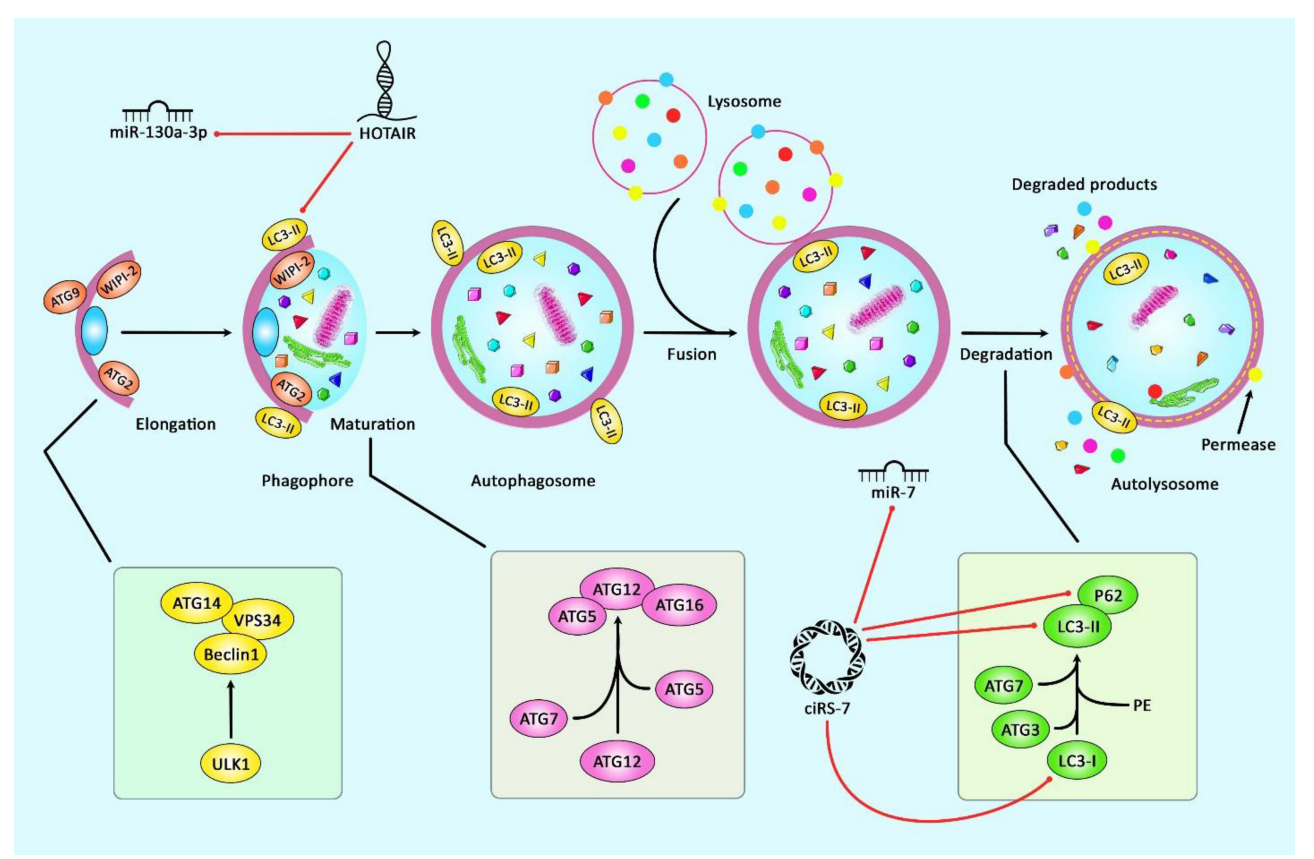

FIGURE 2 | A schematic representation of the role of several ncRNAs in regulating the autophagy cascade in osteoarthritis. Growing evidence confirm that several ncRNAs could regulate the autophagy pathway in osteoarthritis. A recent study have authenticated that IncRNA HOTAIR through downregulating the expression levels of miR-130a-3p, P62, LC3 I, LC3 II could play a significant role in suppressing chondrocyte autophagy in knee osteoarthritis (10). Moreover, according to another research, ciRS-7 through sponging miR-7 and reducing the expression levels of LC3, p62, and Beclin1 could reduce cartilage degradation and attenuate autophagy cascade in osteoarthritis via modulating PI3K/AKT/mTOR pathway (92). Red arrows indicate downregulation of target genes by ncRNAs.

IKZF1 proteins (http://regulome.stanford.edu/) (111). Previous studies have shown the involvement of these proteins in the pathogenesis of $\mathrm{OA}$ or regulation of cellular functions. For instance, suppression of EZH2 can ameliorate development of OA via modulation of $\mathrm{Wnt} / \beta$-catenin pathway (112). E2F6 is involved in the regulation of cell cycle (113). REST encodes a transcriptional repressor which suppresses neuronal genes in non-neuronal tissues (114). IKZF1 is involved in the chromatin remodeling (115). Its role in the regulation of inflammation implies its involvement in the pathogenesis of OA (116).

Although the mechanisms behind involvement of these SNPs in the pathogenesis of OA have not been completely understood, it is possible that these SNPs affect interaction with other target RNAs. Moreover, they can influence expression levels of ncRNAs, thus affecting their regulatory effects.

Identification of risk variants for development of OA can help in development of novel OA therapeutic approaches such as gene editing or gene replacement therapies for OA. Table 8 summarizes these studies.

\section{DIAGNOSTIC ROLES OF ncRNAS IN OA}

Recent investigations have tested the appropriateness of ncRNAs in diagnostic purposes in OA. Circulating ncRNAs (in blood/plasma/ serum) are definitely one of the most interesting biomarkers for OA due to the easy accessibility of sample. Although synovial fluid samples have also been applicable for this purpose, blood/plasma/ serum samples are superior since they are obtained through less invasive methods. For instance, expression levels of H19 in the blood samples could distinguish OA cases from normal subjects with AUC, critical, sensitivity, and specificity values of $0.89,1.87$, $96 \%$, and $85.7 \%$, respectively (9). In a study with limited numbers of cases and controls, GAS5 has been shown to predict the presence of OA with an accuracy of 0.86 (40). The highest diagnostic power among lncRNAs has been achieved by MIR4435-2HG (AUC=0.96) (50). Hsa_circ_0032131 is the only circRNA whose appropriateness for diagnostic strategies in OA has been appraised (117). Table 9 gives an overview of the diagnostic impact of ncRNAs in OA, based on the studies that assessed expression of these transcripts in the circulation of patients. These ncRNAs are merely exemplificative of the work being published in the field.

\section{DISCUSSION}

OA is a multifactorial disorder in which several classes of ncRNAs, including lncRNAs, circRNAs, and miRNAs participate. Notably, the two former classes of ncRNAs mainly exert their effects in this process through acting as molecular sponges for miRNAs. These ncRNAs collaborate to influence chondrocyte proliferation and apoptosis, inflammatory responses, and degradation of ECM. 


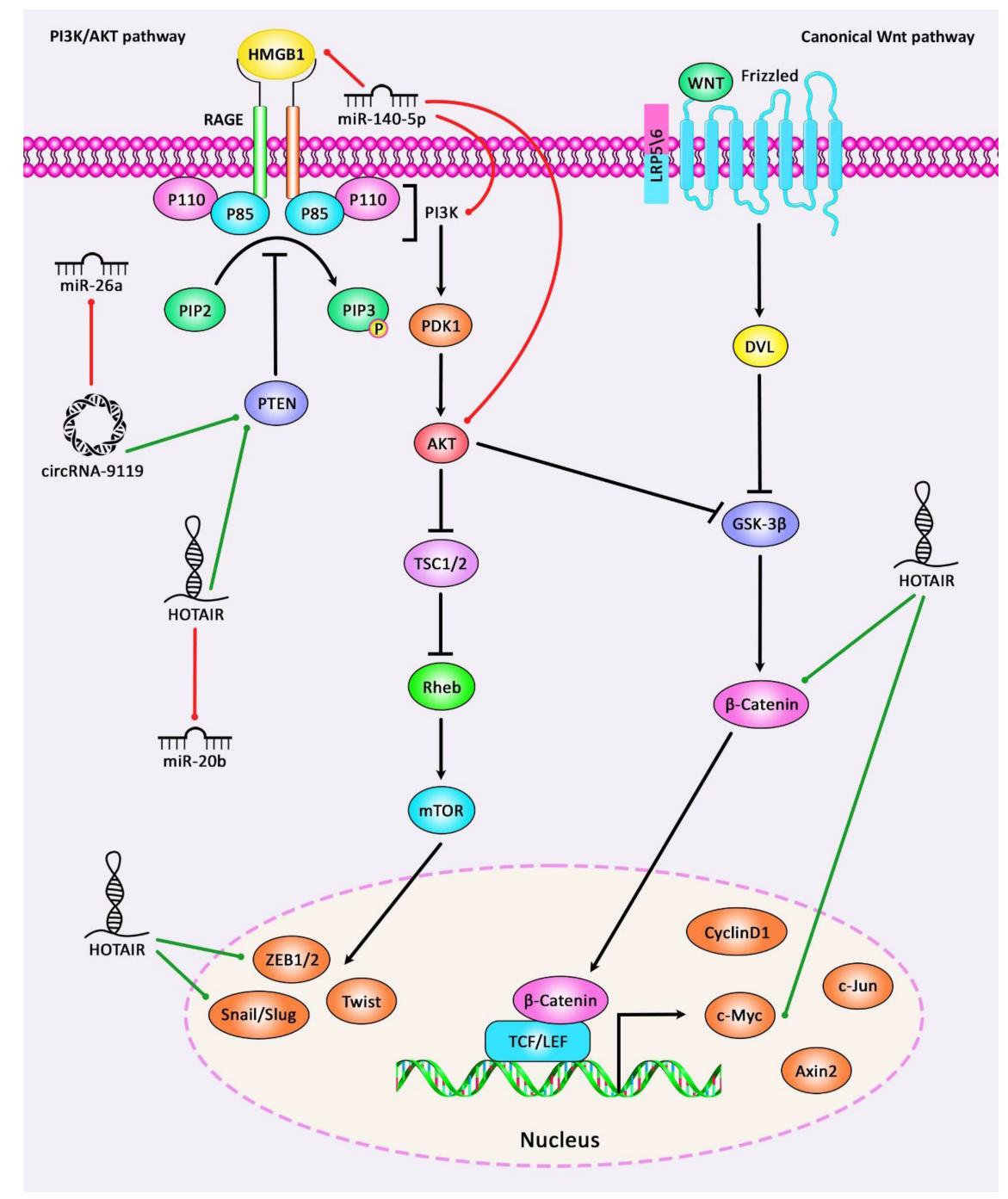

FIGURE 3 | A schematic diagram of the role of some ncRNAs in modulating the PI3K/AKT and Wnt/ $\beta$-catenin signaling pathways in osteoarthritis. Current research has demonstrated that circRNA-9119 via sponging miR-26a could have a significant part in promoting the expression level of PTEN. These circRNA could suppress IL-1ß-induced chondrocyte apoptosis, and possibly triggering Osteoarthritis progression (93). Moreover, another study has denoted that IncRNA HOTAIR could enhance the activation of Wnt/ $\beta$-catenin signaling cascade via downregulating WIF-1 expression in osteoarthritic chondrocytes by promoting the expression levels of C-Myc, ZEB1, and Snail as downstream target genes of Wnt/ $\beta$-catenin signaling, thereby elevating catabolic gene expression and increasing cartilage degradation (7). Green arrows indicate upregulation of target genes via ncRNAs (IncRNAs, circRNAs, and miRNAs), red arrows depict inhibition by these ncRNAs. All the information regarding the role of these ncRNAs in modulating the PI3K/AKT and Wnt/ $\beta$-catenin cascades in osteoarthritis can be seen in Tables 1-7.

Studies that investigated ncRNAs' role in OA can be classified according to their design to in vitro studies, expression assays in clinical samples, and functional studies in animal models. The latter type of studies has provided essential concepts about the role of ncRNAs in this process, as it could assess these transcripts' functional roles in a natural context. Meanwhile, clinical studies, particularly those assessing expression levels of ncRNAs in the peripheral blood, have the advantage of discovering appropriate markers for the diagnosis of $\mathrm{OA}$ and prediction of its course.

NcRNAs can be involved in the fine tuning of the RUNX2 expression and through this rout, they can affect pathogenesis of $\mathrm{OA}$ $(119,120)$. NF-KB, Wnt/ $\beta$-catenin, TGF- $\beta$ and JAK/STAT pathways are the most critical pathways through which ncRNAs exert their effects in the pathogenesis of OA. Based on the functional relevance of these pathways with inflammatory responses, one can conclude that this process has a prominent role in the development of OA. A PPAR- $\alpha$ agonist has been found to inhibit LPS-associated inflammatory responses in synovial fibroblasts through modulation of NF- KB signaling (121). Therefore, ncRNAs associated with these pathways might also represent therapeutic targets for OA.

The cartilage tissue has been mainly studied for the assessment of the ncRNAs' expression. However, limited numbers of studies have investigated the expression of these transcripts in patients' synovial membrane or peripheral blood, evaluating their continuation as non- 
TABLE 8 | Association between ncRNAs polymorphisms and OA.

\begin{tabular}{|c|c|c|c|c|c|}
\hline IncRNA & Number of Clinical Samples & SNP ID & $\begin{array}{l}\text { Nucleotide } \\
\text { change }\end{array}$ & Description & References \\
\hline $\mathrm{H} 19$ & $\begin{array}{l}230 \text { Han Chinese OA patients and } 230 \text { healthy subjects, } \\
\text { matched by age and gender }\end{array}$ & rs217727 & $G>A$ & $\begin{array}{l}\text { "A" allele of the rs } 217727 \text { of } \mathrm{H} 19 \text { increases the } \\
\text { risk of OA. }\end{array}$ & $(109)$ \\
\hline MEG3 & & rs7158663 & $A>G$ & $\begin{array}{l}\text { Having the "A" allele of the rs } 7158663 \text { of MEG3 } \\
\text { increases the risk of OA by } 1.32 \text {. }\end{array}$ & \\
\hline PRNCR1 & $316 \mathrm{OA}$ and 306 healthy cases & rs1456315 & $A>G$ & $\begin{array}{l}\text { Mutant G allele of PRNCR1 rs1456315 increases } \\
\text { the risk of OA. }\end{array}$ & $(110)$ \\
\hline $\mathrm{H} 19$ & 278 Knee OA patients and 289 controls & rs2067051 & $\mathrm{T}>\mathrm{C}$ & $\begin{array}{l}\text { T allele of rs2067051 was associated with lower } \\
\text { susceptibility to knee OA. }\end{array}$ & $(111)$ \\
\hline MEG3 & & rs4378559 & $C>T$ & $\begin{array}{l}\text { T allele of rs } 4378559 \text { was associated with higher } \\
\text { susceptibility to knee OA. }\end{array}$ & \\
\hline HOTTIP & & rs202384 & & $\begin{array}{l}\text { C allele of rs } 2023843 \text { showed boundary positive } \\
\text { in additive genetic model. }\end{array}$ & \\
\hline
\end{tabular}

TABLE 9 | Diagnostic role of ncRNAs in OA.

\begin{tabular}{|c|c|c|c|c|}
\hline IncRNA and Clinical Cases & AUC & Sensitivity & Specificity & Reference \\
\hline H19 expression in blood samples of $103 \mathrm{OA}$ and 100 control subjects & 0.891 & 96.00 & 85.73 & (9) \\
\hline GAS5 expression in the blood samples of 2 groups, OA and control cases, each with 35 cases & 0.860 & - & - & $(40)$ \\
\hline MIR4435-2HG expression measured in blood samples of $78 \mathrm{OA}$ and 58 healthy cases & 0.96 & - & - & (50) \\
\hline PACER expression in plasma samples of $73 \mathrm{OA}$ and 66 healthy controls & 0.95 & - & - & $(52)$ \\
\hline HOTAIR expression in plasma samples of $73 \mathrm{OA}$ and 66 healthy controls & 0.90 & & & \\
\hline ANCR expression in the plasma specimens of $62 \mathrm{OA}$ and 46 healthy cases & 0.8845 & - & - & $(53)$ \\
\hline DILC expression in the plasma of $87 \mathrm{OA}$ and 52 healthy subjects & 0.9321 & - & - & $(54)$ \\
\hline hsa_circ_0032131 expression in blood samples of 25 OA and 25 healthy cases & 0.8062 & 0.90 & 0.65 & $(117)$ \\
\hline Plasma levels of miR-200c-3p in 150 OA cases and 150 controls & 0.755 & - & - & $(118)$ \\
\hline Plasma levels of miR-100-3p in 150 OA cases and 150 controls & 0.845 & - & - & \\
\hline Plasma levels of miR-1826 in 150 OA cases and 150 controls & 0.749 & - & - & \\
\hline
\end{tabular}

invasive markers for the detection of OA. These studies have reported diagnostic power values ranging from 0.80 to 0.96 . Nevertheless, most of these studies have been conducted in limited numbers of cases and controls, precluding the generalization of their results.

The data presented above shows involvement of several ncRNAs in the pathoetiology of OA. This information can be used for design of novel therapeutic options for this disorder. Moreover, it can be used to find genetically susceptible people to OA. However, further assessment of applicability of ncRNAstargeting treatment modalities in animal models is a prerequisite for translation of this filed of basic science into clinical application.

\section{CONCLUSION}

Despite valuable research, this field lacks a comprehensive assessment of different classes of ncRNAs in OA samples. Such

\section{REFERENCES}

1. Chen D, Shen J, Zhao W, Wang T, Han L, Hamilton JL, et al. Osteoarthritis: Toward a Comprehensive Understanding of Pathological Mechanism. Bone Res (2017) 5:16044. doi: 10.1038/boneres.2016.44

2. van Lent PL, Blom AB, Schelbergen RF, Slöetjes A, Lafeber FP, Lems WF, et al. Active Involvement of Alarmins S100A8 and S100A9 in the Regulation of Synovial Activation and Joint Destruction During Mouse and Human study would increase our understanding of the functional relationship between circRNAs, IncRNAs, and miRNAs, thus expanding our knowledge about the pathobiology of OA.

Another gap in this field is the scarcity of assessment of the impact of functional polymorphisms within ncRNAs in conferring OA risk and modulating the disease course. Identification of genomic variants that affect the risk of OA would help in the modification of lifestyle in order to attenuate the course of the disorder.

\section{AUTHOR CONTRIBUTIONS}

SG-F wrote the draft and revised it. MT designed and supervised the study. CP and MM revised the draft. AT collected the data and designed the figures and tables. All the authors read and approved the submitted version. 
5. Mercer TR, Dinger ME, Sunkin SM, Mehler MF, Mattick JS. Specific Expression of Long Noncoding RNAs in the Mouse Brain. Proc Natl Acad Sci (2008) 105(2):716-21. doi: 10.1073/pnas.0706729105

6. Cabili MN, Trapnell C, Goff L, Koziol M, Tazon-Vega B, Regev A, et al. Integrative Annotation of Human Large Intergenic Noncoding RNAs Reveals Global Properties and Specific Subclasses. Genes Dev (2011) 25 (18):1915-27. doi: 10.1101/gad.17446611

7. Yang Y, Xing D, Wang Y, Jia H, Li B, Li JJ. A Long Non-Coding RNA, HOTAIR, Promotes Cartilage Degradation in Osteoarthritis by Inhibiting WIF-1 Expression and Activating Wnt Pathway. BMC Mol Cell Biol (2020) 21(1):1-11. doi: 10.1186/s12860-020-00299-6

8. Zhang X, Liu X, Ni X, Feng P, Wang Y. Long Non-Coding RNA H19 Modulates Proliferation and Apoptosis in Osteoarthritis via Regulating miR-106a-5p. J Biosci (2019) 44(6):128. doi: 10.1007/s12038-019-9943-x

9. Liwu Z, Yang W, Qiang CHENG BS, Lei ZHANG SC. The Expression and Diagnostic Value of LncRNA H19 in the Blood of Patients With Osteoarthritis. Iranian J Public Health (2020) 49(8):1494. doi: 10.18502/ ijph.v49i8.3893

10. He B, Jiang D. HOTAIR-Induced Apoptosis Is Mediated by Sponging miR130a-3p to Repress Chondrocyte Autophagy in Knee Osteoarthritis. Cell Biol Int (2020) 44(2):524-35. doi: 10.1002/cbin.11253

11. Li Xp, Wei X, Wang Sq, Sun G, Zhao Yc, Yin H, et al. Differentiation Antagonizing Non-Protein Coding RNA Knockdown Alleviates Lipopolysaccharide-Induced Inflammatory Injury and Apoptosis in Human Chondrocyte Primary Chondrocyte Cells Through Upregulating miRNA-19a-3p. Orthopaedic Surg (2020). doi: 10.1111/os.12845

12. van Gastel N, Stegen S, Eelen G, Schoors S, Carlier A, Daniëls VW, et al. Lipid Availability Determines Fate of Skeletal Progenitor Cells via SOX9. Nature (2020) 579(7797):111-7. doi: 10.1038/s41586-020-2050-1

13. Fang P, Zhang L, Hu Y, Zhang L, Zhou L. Long Non-Coding RNA DANCR Induces Chondrogenesis by Regulating the miR-1275/MMP-13 Axis in Synovial Fluid-Derived Mesenchymal Stem Cells. Eur Rev Med Pharmacol Sci (2019) 23(23):10459-69. doi: 10.26355/eurrev_201912_19685

14. Nanus DE, Wijesinghe SN, Pearson MJ, Hadjicharalambous MR, Rosser A, Davis ET, et al. Regulation of the Inflammatory Synovial Fibroblast Phenotype by Metastasis-Associated Lung Adenocarcinoma Transcript 1 Long Noncoding RNA in Obese Patients With Osteoarthritis. Arthritis Rheumatol (2020) 72(4):609-19. doi: 10.1002/art.41158

15. Liu F, Liu X, Yang Y, Sun Z, Deng S, Jiang Z, et al. NEAT1/miR-193a-3p/ SOX5 Axis Regulates Cartilage Matrix Degradation in Human Osteoarthritis. Cell Biol Int (2020) 44(4):947-57. doi: 10.1002/cbin.11291

16. Xiao P, Zhu X, Sun J, Zhang Y, Qiu W, Li J, et al. LncRNA NEAT1 Regulates Chondrocyte Proliferation and Apoptosis via Targeting miR-543/PLA2G4A Axis. Hum Cell (2021) 34:60-75. doi: 10.1007/s13577-020-00433-8

17. Tu Y, Ma T, Wen T, Yang T, Xue L, Cai M, et al. MicroRNA-377-3p Alleviates IL-1 $\beta$-Caused Chondrocyte Apoptosis and Cartilage Degradation in Osteoarthritis in Part by Downregulating Itga6. Biochem Biophys Res Commun (2020) 523(1):46-53. doi: 10.1016/j.bbrc.2019.11.186

18. Li L, Lv G, Wang B, Kuang L. XIST/miR-376c-5p/OPN Axis Modulates the Influence of Proinflammatory M1 Macrophages on Osteoarthritis Chondrocyte Apoptosis. J Cell Physiol (2020) 235(1):281-93. doi: 10.1002/jcp.28968

19. Wang T, Liu Y, Wang Y, Huang X, Zhao W, Zhao Z. Long Non-Coding RNA XIST Promotes Extracellular Matrix Degradation by Functioning as a Competing Endogenous RNA of miR-1277-5p in Osteoarthritis. Int J Mol Med (2019) 44(2):630-42. doi: 10.3892/ijmm.2019.4240

20. Sun P, Wu Y, Li X, Jia Y. miR-142-5p Protects Against Osteoarthritis Through Competing With lncRNA XIST. J Gene Med (2020) 22(4):e3158. doi: $10.1002 /$ jgm. 3158

21. Chen H, Yang S, Shao R. Long Non-Coding XIST Raises Methylation of TIMP-3 Promoter to Regulate Collagen Degradation in Osteoarthritic Chondrocytes After Tibial Plateau Fracture. Arthritis Res Ther (2019) 21 (1):271. doi: 10.1186/s13075-019-2033-5

22. Zhang G, Zhang Q, Zhu J, Tang J, Nie M. LncRNA ARFRP1 Knockdown Inhibits LPS-Induced the Injury of Chondrocytes by Regulation of NF- $\mathrm{kb}$ Pathway Through Modulating miR-15a-5p/TLR4 Axis. Life Sci (2020) 261:118429. doi: 10.1016/j.lfs.2020.118429

23. Chen K, Fang H, Xu N. LncRNA LOXL1-AS1 Is Transcriptionally Activated by JUND and Contributes to Osteoarthritis Progression via Targeting the
miR-423-5p/KDM5C Axis. Life Sci (2020) 258:118095. doi: 10.1016/ j.lfs. 2020.118095

24. Liu C, Ren S, Zhao S, Wang Y. LncRNA MALAT1/MiR-145 Adjusts IL-1 $\beta$ Induced Chondrocytes Viability and Cartilage Matrix Degradation by Regulating ADAMTS5 in Human Osteoarthritis. Yonsei Med J (2019) 60 (11):1081-92. doi: 10.3349/ymj.2019.60.11.1081

25. Luo X, Wang J, Wei X, Wang S, Wang A. Knockdown of lncRNA MFI2-AS1 Inhibits Lipopolysaccharide-Induced Osteoarthritis Progression by miR130a-3p/TCF4. Life Sci (2020) 240:117019. doi: 10.1016/j.lfs.2019.117019

26. Zhu Y, Jiang D. LncRNA PART1 Modulates Chondrocyte Proliferation, Apoptosis, and Extracellular Matrix Degradation in Osteoarthritis via Regulating miR-373-3p/SOX4 Axis. Eur Rev Med Pharmacol Sci (2019) 23 (19):8175-85. doi: 10.26355/eurrev_201910_19124

27. Ding L-B, Li Y, Liu G-Y, Li T-H, Li F, Guan J, et al. Long Non-Coding RNA PVT1, a Molecular Sponge of miR-26b, Is Involved in the Progression of Hyperglycemia-Induced Collagen Degradation in Human Chondrocytes by Targeting CTGF/TGF- $\beta$ Signal Ways. Innate Immun (2020) 26(3):204-14. doi: $10.1177 / 1753425919881778$

28. Meng Y, Qiu S, Sun L, Zuo J. Knockdown of Exosome-Mediated lnc-PVT1 Alleviates Lipopolysaccharide-Induced Osteoarthritis Progression by Mediating the HMGB1/TLR4/NF-кb Pathway via Mir-93-5p. Mol Med Rep (2020) 22(6):5313-25. doi: 10.3892/mmr.2020.11594

29. Huang B, Yu H, Li Y, Zhang W, Liu X. Upregulation of Long Noncoding TNFSF10 Contributes to Osteoarthritis Progression Through the miR-3763p/FGFR1 Axis. J Cell Biochem (2019) 120(12):19610-20. doi: 10.1002/ jcb. 29267

30. Yu C, Shi D, Li Z, Wan G, Shi X. Long Noncoding RNA CHRF Exacerbates IL-6Induced Inflammatory Damages by Downregulating microRNA-146a in ATDC5 Cells. J Cell Physiol (2019) 234(12):21851-9. doi: 10.1002/jcp.28749

31. Huang T, Wang J, Zhou Y, Zhao Y, Hang D, Cao Y. LncRNA CASC2 Is UpRegulated in Osteoarthritis and Participates in the Regulation of IL-17 Expression and Chondrocyte Proliferation and Apoptosis. Biosci Rep (2019) 39(5). doi: 10.1042/BSR20182454

32. Wang Y, Cao L, Wang Q, Huang J, Xu S. LncRNA FOXD2-AS1 Induces Chondrocyte Proliferation Through Sponging miR-27a-3p in Osteoarthritis. Artif Cells Nanomed Biotechnol (2019) 47(1):1241-7. doi: 10.1080/ 21691401.2019.1596940

33. Hu Y, Li S, Zou Y. Knockdown of LncRNA H19 Relieves LPS-Induced Damage by Modulating miR-130a in Osteoarthritis. Yonsei Med J (2019) 60 (4):381-8. doi: 10.3349/ymj.2019.60.4.381

34. Li Y, Li Z, Li C, Zeng Y, Liu Y. Long Noncoding RNA TM1P3 Is Involved in Osteoarthritis by Mediating Chondrocyte Extracellular Matrix Degradation. J Cell Biochem (2019) 120(8):12702-12. doi: 10.1002/jcb.28539

35. Liu G, Wang Y, Zhang M, Zhang Q. Long Non-Coding RNA THRIL Promotes LPS-Induced Inflammatory Injury by Down-Regulating microRNA-125b in ATDC5 Cells. Int Immunopharmacol (2019) 66:35461. doi: 10.1016/j.intimp.2018.11.038

36. Fan H, Ding L, Yang Y. IncRNA SNHG16 Promotes the Occurrence of Osteoarthritis by Sponging Mir-373-3p. Mol Med Rep (2020) 23(2):1. doi: 10.3892/mmr.2020.11756

37. Zhang P, Sun J, Liang C, Gu B, Xu Y, Lu H, et al. lncRNA Ighcyl Acts as a ceRNA to Regulate Macrophage Inflammation via the miR-6891-3p/TLR4 Axis in Osteoarthritis. Mediators Inflamm (2020) 2020. doi: 10.1155/2020/9743037

38. Zhang H, Li J, Shao W, Shen N. LncRNA CTBP1-AS2 Is Upregulated in Osteoarthritis and Increases the Methylation of miR-130a Gene to Inhibit Chondrocyte Proliferation. Clin Rheumatol (2020). doi: 10.1007/s10067020-05113-4

39. Zhang Y, Dong Q, Sun X. Positive Feedback Loop LINC00511/miR-150-5p/ SP1 Modulates Chondrocyte Apoptosis and Proliferation in Osteoarthritis. DNA Cell Biol (2020) 39(9):1506-12. doi: 10.1089/dna.2020.5718

40. Gao S, Yu Y, Wan L, Liu Z, Lin J. LncRNA GAS5 Induces Chondrocyte Apoptosis by Down-Regulating miR-137. Eur Rev Med Pharmacol Sci (2020) 24(21):10984-91. doi: 10.26355/eurrev_202011_23582

41. Zhang Y, Ma L, Wang C, Wang L, Guo Y, Wang G. Long Noncoding RNA LINC00461 Induced Osteoarthritis Progression by Inhibiting miR-30a-5p. Aging (Albany NY) (2020) 12(5):4111. doi: 10.18632/aging.102839

42. Lian L, Xi X. Long Non-Coding RNA XIST Protects Chondrocytes ATDC5 and CHON-001 From IL-1ß-Induced Injury via Regulating miR-653-5p/ 
SIRT1 Axis. J Biol Regul Homeostatic Agents (2020) 34(2):379-91. doi: 10.23812/19-549-A-65

43. Wang Z, Hao J, Chen D. Long Noncoding RNA Nuclear Enriched Abundant Transcript 1 (NEAT1) Regulates Proliferation, Apoptosis, and Inflammation of Chondrocytes via the miR-181a/Glycerol-3-Phosphate Dehydrogenase 1Like (GPD1L) Axis. Med Sci Monit (2019) 25:8084-94. doi: 10.12659/ MSM.918416

44. Tian F, Wang J, Zhang Z, Yang J. LncRNA SNHG7/miR-34a-5p/SYVN1 Axis Plays a Vital Role in Proliferation, Apoptosis and Autophagy in Osteoarthritis. Biol Res (2020) 53(1):1-11. doi: 10.1186/s40659-020-00275-6

45. Xu J, Pei Y, Lu J, Liang X, Li Y, Wang J, et al. LncRNA SNHG7 Alleviates IL$1 \beta$-Induced Osteoarthritis by Inhibiting miR-214-5p-Mediated PPARGC1B Signaling Pathways. Int Immunopharmacol (2020) 90:107150. doi: 10.1016/ j.intimp.2020.107150

46. Gao L, Zeng H, Zhang T, Mao C, Wang Y, Han Z, et al. MicroRNA-21 Deficiency Attenuated Atherogenesis and Decreased Macrophage Infiltration by Targeting Dusp-8. Atherosclerosis (2019) 291:78-86. doi: 10.1016/j.atherosclerosis.2019.10.003

47. Qi K, Lin R, Xue C, Liu T, Wang Y, Zhang Y, et al. Long Non-Coding RNA (IncRNA) CAIF Is Downregulated in Osteoarthritis and Inhibits LPS-Induced Interleukin 6 (IL-6) Upregulation by Downregulation of miR-1246. Med Sci Monit: Int Med J Exp Clin Res (2019) 25:8019. doi: 10.12659/MSM.917135

48. Lu C, Li Z, Hu S, Cai Y, Peng K. LncRNA PART-1 Targets TGFBR2/Smad3 to Regulate Cell Viability and Apoptosis of Chondrocytes via Acting as miR590-3p Sponge in Osteoarthritis. J Cell Mol Med (2019) 23(12):8196-205. doi: $10.1111 / \mathrm{jcmm} .14690$

49. Mei X, Tong J, Zhu W, Zhu Y. IncRNA-NR024118 Overexpression Reverses LPS-induced Inflammatory Injury and Apoptosis via NF- $\mathrm{kb} / \mathrm{Nrf2}$ Signaling in ATDC5 Chondrocytes. Mol Med Rep (2019) 20(4):3867-73. doi: 10.3892/ mmr.2019.10639

50. Xiao Y, Bao Y, Tang L, Wang L. LncRNA MIR4435-2HG Is Downregulated in Osteoarthritis and Regulates Chondrocyte Cell Proliferation and Apoptosis. J Orthopaedic Surg Res (2019) 14(1):247. doi: 10.1186/s13018019-1278-7

51. Lei J, Fu Y, Zhuang Y, Zhang K, Lu D. LncRNA SNHG1 Alleviates IL-1ßInduced Osteoarthritis by Inhibiting miR-16-5p-Mediated P38 MAPK and NF-kb Signaling Pathways. Biosci Rep (2019) 39(9):BSR20191523. doi: 10.1042/BSR20191523

52. Jiang M, Liu J, Luo T, Chen Q, Lu M, Meng D. LncRNA PACER Is DownRegulated in Osteoarthritis and Regulates Chondrocyte Apoptosis and IncRNA HOTAIR Expression. Biosci Rep (2019) 39(6). doi: 10.1042/ BSR20190404

53. Li Q, Zhang Z, Guo S, Tang G, Lu W, Qi X. LncRNA ANCR Is Positively Correlated With Transforming Growth Factor- $\beta 1$ in Patients With Osteoarthritis. J Cell Biochem (2019) 120(9):14226-32. doi: 10.1002/jcb.28881

54. Huang J, Liu L, Yang J, Ding J, Xu X. IncRNA DILC Is Downregulated in Osteoarthritis and Regulates IL-6 Expression in Chondrocytes. J Cell Biochem (2019) 120(9):16019-24. doi: 10.1002/jcb.28880

55. Chu P, Wang Q, Wang Z, Gao C. Long Non-Coding RNA Highly Up-Regulated in Liver Cancer Protects Tumor Necrosis Factor-Alpha-Induced Inflammatory Injury by Down-Regulation of microRNA-101 in ATDC5 Cells. Int Immunopharmacol (2019) 72:148-58. doi: 10.1016/j.intimp.2019.04.004

56. Ying H, Wang Y, Gao Z, Zhang Q. Long Non-Coding RNA Activated by Transforming Growth Factor Beta Alleviates Lipopolysaccharide-Induced Inflammatory Injury via Regulating microRNA-223 in ATDC5 Cells. Int Immunopharmacol (2019) 69:313-20. doi: 10.1016/j.intimp.2019.01.056

57. Liu Y, Li Q, Hosen MR, Zietzer A, Flender A, Levermann P, et al. Atherosclerotic Conditions Promote the Packaging of Functional microRNA-92a-3p Into Endothelial Microvesicles. Circ Res (2019) 124 (4):575-87. doi: 10.1161/CIRCRESAHA.118.314010

58. Jiang H, Pang H, Wu P, Cao Z, Li Z, Yang X. LncRNA SNHG5 Promotes Chondrocyte Proliferation and Inhibits Apoptosis in Osteoarthritis by Regulating miR-10a-5p/H3F3B Axis. Connect Tissue Res (2020), 1-10. doi: 10.1080/03008207.2020.1825701

59. Zhang H, Li J, Shao W, Shen N. LncRNA SNHG9 Is Downregulated in Osteoarthritis and Inhibits Chondrocyte Apoptosis by Downregulating miR34a Through Methylation. BMC Musculoskelet Disord (2020) 21(1):1-7. doi: 10.1186/s12891-020-03497-7
60. Liang X, Wang L, Wang M, Liu Z, Liu X, Zhang B, et al. MicroRNA-124 Inhibits Macrophage Cell Apoptosis via Targeting P38/MAPK Signaling Pathway in Atherosclerosis Development. Aging (Albany NY) (2020) 12 (13):13005. doi: 10.18632/aging.103387

61. Zhi L, Zhao J, Zhao H, Qing Z, Liu H, Ma J. Downregulation of LncRNA OIP5-AS1 Induced by IL-1 $\beta$ Aggravates Osteoarthritis via Regulating miR29b-3p/PGRN. Cartilage (2020) 1947603519900801. doi: 10.1177/ 1947603519900801

62. Luo J, Wu C, Liu Y, Fan J, Shang X, Liu R, et al. LncRNA CYTOR Regulates Chondrocyte Apoptosis in Osteoarthritis by Acting as a CeRNA for miR10a-5p. (2020). doi: 10.21203/rs.3.rs-95416/v1

63. Xue H, Yu P, Wang W, Niu Y, Li X. The Reduced lncRNA NKILA Inhibited Proliferation and Promoted Apoptosis of Chondrocytes via miR-145/SP1/ NF-kb Signaling in Human Osteoarthritis. Eur Rev Med Pharmacol Sci (2020) 24(2):535-48. doi: 10.26355/eurrev_202001_20030

64. Si Z, Zhou S, Shen Z, Luan F, Yan J. IncRNA HAND2-AS1 Is Down Regulated in Osteoarthritis and Regulates IL-6 Expression in Chondrocyte. J Orthopaedic Surg Res (2020). doi: 10.21203/rs.3.rs-93180/v1

65. Lü G, Li L, Wang B, Kuang L. LINC00623/miR-101/HRAS Axis Modulates IL-1 $\beta$-Mediated ECM Degradation, Apoptosis and Senescence of Osteoarthritis Chondrocytes. Aging (Albany NY) (2020) 12(4):3218. doi: 10.18632/aging.102801

66. Ni S, Xu C, Zhuang C, Zhao G, Li C, Wang Y, et al. LncRNA LUADT1 Regulates miR-34a/SIRT1 to Participate in Chondrocyte Apoptosis. J Cell Biochem (2020). doi: 10.1002/jcb.29637

67. Rotllan N, Price N, Pati P, Goedeke L, Fernández-Hernando C. microRNAs in Lipoprotein Metabolism and Cardiometabolic Disorders. Atherosclerosis (2016) 246:352-60. doi: 10.1016/j.atherosclerosis.2016.01.025

68. Macfarlane L-A, Murphy PR. MicroRNA: Biogenesis, Function and Role in Cancer. Curr Genomics (2010) 11(7):537-61. doi: 10.2174/138920210793175895

69. Cheng F, Hu H, Sun K, Yan F, Geng Y. miR-455-3p Enhances Chondrocytes Apoptosis and Inflammation by Targeting COL2A1 in the In Vitro Osteoarthritis Model. Biosci Biotechnol Biochem (2020) 84(4):695-702. doi: 10.1080/09168451.2019.1690974

70. Wen X, Li H, Sun H, Zeng A, Lin R, Zhao J, et al. MiR-455-3p Reduces Apoptosis and Alleviates Degeneration of Chondrocyte Through Regulating PI3K/AKT Pathway. Life Sci (2020) 253:117718. doi: 10.1016/ j.lfs. 2020.117718

71. Wang W-T, Huang Z-P, Sui S, Liu J-H, Yu D-M, Wang W-B. microRNA1236 Promotes Chondrocyte Apoptosis in Osteoarthritis via Direct Suppression of PIK3R3. Life Sci (2020) 253:117694. doi: 10.1016/ j.lfs.2020.117694

72. Yang F, Huang R, Ma H, Zhao X, Wang G. miRNA-411 Regulates Chondrocyte Autophagy in Osteoarthritis by Targeting Hypoxia-Inducible Factor 1 Alpha (HIF-1 $\alpha$ ). Med Sci Monit: Int Med J Exp Clin Res (2020) 26: e921155-1. doi: 10.12659/MSM.921155

73. Guo Y, Tian L, Du X, Deng Z. MiR-203 Regulates Estrogen Receptor $\alpha$ and Cartilage Degradation in IL-1 $\beta$-Stimulated Chondrocytes. J Bone Mineral Metab (2020) 38:346-56. doi: 10.1007/s00774-019-01062-4

74. Chao Y, Zhang L, Zhang X, Ma C, Chen Z. Expression of MiR-140 and MiR199 in Synovia and Its Correlation With the Progression of Knee Osteoarthritis. Med Sci Monit: Int Med J Exp Clin Res (2020) 26:e9181741. doi: 10.12659/MSM.918174

75. Jin Z, Ren J, Qi S. Exosomal miR-9-5p Secreted by Bone Marrow-Derived Mesenchymal Stem Cells Alleviates Osteoarthritis by Inhibiting Syndecan-1. Cell Tissue Res (2020) 381(1):99-114. doi: 10.1007/s00441-020-03193-x

76. Li F, Yao J, Hao Q, Duan Z. miRNA-103 Promotes Chondrocyte Apoptosis by Down-Regulation of Sphingosine Kinase-1 and Ameliorates PI3K/AKT Pathway in Osteoarthritis. Biosci Rep (2019) 39(10). doi: 10.1042/ BSR20191255

77. Cai C, Min S, Yan B, Liu W, Yang X, Li L, et al. MiR-27a Promotes the Autophagy and Apoptosis of IL-1 $\beta$ Treated-Articular Chondrocytes in Osteoarthritis Through PI3K/AKT/mTOR Signaling. Aging (Albany NY) (2019) 11(16):6371. doi: 10.18632/aging.102194

78. Wang Y, Shen S, Li Z, Li W, Weng X. MIR-140-5p Affects Chondrocyte Proliferation, Apoptosis, and Inflammation by Targeting HMGB1 in Osteoarthritis. Inflamm Res (2020) 69(1):63-73. doi: 10.1007/s00011-01901294-0 
79. Wang W, Han X, Zhao T, Zhang X, Qu P, Zhao H. AGT, Targeted by miR149-5p, Promotes IL-6-Induced Inflammatory Responses of Chondrocytes in Osteoarthritis via Activating JAK2/STAT3 Pathway. Clin Exp Rheumatol (2020).

80. Sun Y, Kang S, Pei S, Sang C, Huang Y. MiR93-5p Inhibits Chondrocyte Apoptosis in Osteoarthritis by Targeting lncRNA Casc2. BMC Musculoskelet Disord (2020) 21(1):1-7. doi: 10.1186/s12891-019-3025-y

81. Jin Z, Ren J, Qi S. Human Bone Mesenchymal Stem Cells-Derived Exosomes Overexpressing microRNA-26a-5p Alleviate Osteoarthritis via DownRegulation of PTGS2. Int Immunopharmacol (2020) 78:105946. doi: 10.1016/j.intimp.2019.105946

82. Tao T, Zhang Y, Wei H, Heng K. Downregulation of IRAK3 by miR-33b-3p Relieves Chondrocyte Inflammation and Apoptosis in an In Vitro Osteoarthritis Model. Biosci Biotechnol Biochem (2020). doi: 10.1093/bbb/ zbaa105

83. Zhong G, Long H, Ma S, Shunhan Y, Li J, Yao J. miRNA-335-5p Relieves Chondrocyte Inflammation by Activating Autophagy in Osteoarthritis. Life Sci (2019) 226:164-72. doi: 10.1016/j.lfs.2019.03.071

84. Hu S, Mao G, Zhang Z, Wu P, Wen X, Liao W, et al. MicroRNA-320c Inhibits Development of Osteoarthritis Through Downregulation of Canonical Wnt Signaling Pathway. Life Sci (2019) 228:242-50. doi: 10.1016/j.lfs.2019.05.011

85. Xin P, Xu W, Zhu X, Li C, Zheng Y, Zheng T, et al. Protective Autophagy or Autophagic Death: Effects of BEZ235 on Chronic Myelogenous Leukemia. Cancer Manage Res (2019) 11:7933. doi: 10.2147/CMAR.S204472

86. Ippen FM, Alvarez-Breckenridge CA, Kuter BM, Fink AL, Bihun IV, Lastrapes M, et al. The Dual PI3K/mTOR Pathway Inhibitor GDC-0084 Achieves Antitumor Activity in PIK3CA-Mutant Breast Cancer Brain Metastases. Clin Cancer Res (2019) 25: (11):3374-83. doi: 10.1158/1078-0432.CCR-18-3049

87. Wu Y, Zhang Y, Zhang Y, Wang JJ. CircRNA Hsa_Circ_0005105 Upregulates NAMPT Expression and Promotes Chondrocyte Extracellular Matrix Degradation by Sponging miR-26a. Cell Biol Int (2017) 41(12):12839. doi: 10.1002/cbin.10761

88. Huang W, Wu X, Xue Y, Zhou Y, Xiang H, Yang W, et al. MicroRNA-3614 Regulates Inflammatory Response via Targeting TRAF6-Mediated MAPKs and NF-kb Signaling in the Epicardial Adipose Tissue With Coronary Artery Disease. Int J Cardiol (2020). doi: 10.1016/j.ijcard.2020.09.045

89. Chen G, Liu T, Yu B, Wang B, Peng Q. CircRNA-UBE2G1 Regulates LPSInduced Osteoarthritis Through miR-373/HIF-1a Axis. Cell Cycle (2020) 19 (13):1696-705. doi: 10.1080/15384101.2020.1772545

90. Li Z, Yuan B, Pei Z, Zhang K, Ding Z, Zhu S, et al. Circ_0136474 and MMP13 Suppressed Cell Proliferation by Competitive Binding to miR-127-5p in Osteoarthritis. J Cell Mol Med (2019) 23(10):6554-64. doi: 10.1111/ jcmm. 14400

91. Taheri M, Noroozi R, Aghaei K, Omrani MD, Ghafouri-Fard S. The Rs594445 in MOCOS Gene Is Associated With Risk of Autism Spectrum Disorder. Metab Brain Dis (2020) 35(3):497-501. doi: 10.1007/s11011-01900524-y

92. Zhou X, Li J, Zhou Y, Yang Z, Yang H, Li D, et al. Down-Regulated ciRS-7/ Up-Regulated miR-7 Axis Aggravated Cartilage Degradation and Autophagy Defection by PI3K/AKT/mTOR Activation Mediated by IL17A in Osteoarthritis. Aging (Albany NY) (2020) 12(20):20163. doi: 10.18632/aging. 103731

93. Chen C, Yin P, Hu S, Sun X, Li B. Circular RNA-9119 Protects IL-1ßTreated Chondrocytes From Apoptosis in an Osteoarthritis Cell Model by Intercepting the microRNA-26a/PTEN Axis. Life Sci (2020) 256:117924. doi: 10.1016/j.lfs.2020.117924

94. Shen S, Wu Y, Chen J, Xie Z, Huang K, Wang G, et al. CircSERPINE2 Protects Against Osteoarthritis by Targeting miR-1271 and ETS-Related Gene. Ann Rheum Dis (2019) 78(6):826-36. doi: 10.1136/annrheumdis-2018-214786

95. Zhou JL, Deng S, Fang HS, Xj Du, Peng H, Hu Qj. Circular RNA Circankrd36 Regulates Caszl by Targeting miR-599 to Prevent Osteoarthritis Chondrocyte Apoptosis and Inflammation. J Cell Mol Med (2020). doi: $10.1111 / \mathrm{jcmm} .15884$

96. Chen Y, Zhang L, Li E, Zhang G, Hou Y, Yuan W, et al. Long-Chain NonCoding RNA HOTAIR Promotes the Progression of Osteoarthritis via Sponging miR-20b/PTEN Axis. Life Sci (2020) 253:117685. doi: 10.1016/ j.lfs. 2020.117685
97. Yang DW, Zhang X, Qian GB, Jiang MJ, Wang P, Wang KZ. Downregulation of Long Noncoding RNA LOC101928134 Inhibits the Synovial Hyperplasia and Cartilage Destruction of Osteoarthritis Rats Through the Activation of the Janus Kinase/Signal Transducers and Activators of Transcription Signaling Pathway by Upregulating Ifnal. J Cell Physiol (2019) 234(7):10523-34. doi: 10.1002/jcp.27730

98. Lu M, Zhou E. Long Noncoding RNA LINC00662-miR-15b-5p Mediated GPR120 Dysregulation Contributes to Osteoarthritis. Pathol Int (2020) 70 (3):155-65. doi: 10.1111/pin.12875

99. Tao H, Cheng L, Yang R. Downregulation of miR-34a Promotes Proliferation and Inhibits Apoptosis of Rat Osteoarthritic Cartilage Cells by Activating PI3K/Akt Pathway. Clin Interventions Aging (2020) 15:373. doi: 10.2147/CIA.S241855

100. Zhang M, Wang Z, Li B, Sun F, Chen A, Gong M. Identification of microRNA-363-3p as an Essential Regulator of Chondrocyte Apoptosis in Osteoarthritis by Targeting NRF1 Through the P53-Signaling Pathway. Mol Med Rep (2020) 21(3):1077-88. doi: 10.3892/mmr.2020.10940

101. Mao D, Wu M, Wei J, Zhou X, Yang L, Chen F. MicroRNA-101a-3p Could be Involved in the Pathogenesis of Temporomandibular Joint Osteoarthritis by Mediating UBE2D1 and FZD4. J Oral Pathol Med (2020). doi: 10.1111/ jop.13131

102. Zhou Z-B, Huang G-X, Fu Q, Han B, Lu J-J, Chen A-M, et al. circRNA. 33186 Contributes to the Pathogenesis of Osteoarthritis by Sponging miR127-5p. Mol Ther (2019) 27(3):531-41. doi: 10.1016/j.ymthe.2019.01.006

103. Zhou Z-b, Du D, Huang G-x, Chen A, Zhu L. Circular RNA Atp9b, a Competing Endogenous RNA, Regulates the Progression of Osteoarthritis by Targeting miR-138-5p. Gene (2018) 646:203-9. doi: 10.1016/j.gene.2017.12.064

104. Malemud CJ. Negative Regulators of JAK/STAT Signaling in Rheumatoid Arthritis and Osteoarthritis. Int J Mol Sci (2017) 18(3):484. doi: 10.3390/ ijms18030484

105. Rigoglou S, Papavassiliou AG. The NF-kb Signalling Pathway in Osteoarthritis. Int J Biochem Cell Biol (2013) 45(11):2580-4. doi: 10.1016/j.biocel.2013.08.018

106. Duan R, Xie H, Liu Z-Z. The Role of Autophagy in Osteoarthritis. Front Cell Dev Biol (2020) 8:1437. doi: 10.3389/fcell.2020.608388

107. Wang Y, Fan X, Xing L, Tian F. Wnt Signaling: A Promising Target for Osteoarthritis Therapy. Cell Commun Signaling (2019) 17(1):1-14. doi: 10.1186/s12964-019-0411-x

108. Sun K, Luo J, Guo J, Yao X, Jing X, Guo F. The PI3K/AKT/mTOR Signaling Pathway in Osteoarthritis: A Narrative Review. Osteoarthritis Cartilage (2020) 28(4):400-9. doi: 10.1016/j.joca.2020.02.027

109. Wang H, Li J, Cheng Y, Yao J. Association of Long-Chain Noncoding RNA H19 and MEG3 Gene Polymorphisms and Their Interaction With Risk of Osteoarthritis in a Chinese Han Population. Genet Testing Mol Biomarkers (2020). doi: 10.1089/gtmb.2019.0230

110. Wang Q, Wu Y, Li F, Zhu H, Zhou B, Qian Y, et al. Association of Genetic Polymorphisms in Immune-Related IncRNA With Osteoarthritis Susceptibility in Chinese Han Population. Personalized Med (2018) 15 (2):103-10. doi: 10.2217/pme-2017-0072

111. Wang K, Chu M, Ding W, Jiang Q. Putative Functional Variants of IncRNA Identified by RegulomeDB Were Associated With Knee Osteoarthritis Susceptibility. BMC Musculoskelet Disord (2018) 19(1):1-6. doi: 10.1186/ s12891-018-2197-1

112. Chen L, Wu Y, Wu Y, Wang Y, Sun L, Li F. The Inhibition of EZH2 Ameliorates Osteoarthritis Development Through the Wnt/ $\beta$-Catenin Pathway. Sci Rep (2016) 6:29176. doi: 10.1038/srep29176

113. Ogawa H, Ishiguro K-I, Gaubatz S, Livingston DM, Nakatani Y. A Complex With Chromatin Modifiers That Occupies E2F-And MycResponsive Genes in G0 Cells. Science (2002) 296(5570):1132-6. doi: $10.1126 /$ science. 1069861

114. Bayram Y, White JJ, Elcioglu N, Cho MT, Zadeh N, Gedikbasi A, et al. REST Final-Exon-Truncating Mutations Cause Hereditary Gingival Fibromatosis. Am J Hum Genet (2017) 101(1):149-56. doi: 10.1016/j.ajhg.2017.06.006

115. Ueta M, Hamuro J, Nishigaki H, Nakamura N, Shinomiya K, Mizushima K, et al. Mucocutaneous Inflammation in the Ikaros Family Zinc Finger 1-Keratin 5-Specific Transgenic Mice. Allergy (2018) 73(2):395-404. doi: 10.1111/all. 13308

116. Chrousos GP, Kino T. Ikaros Transcription Factors: Flying Between Stress and Inflammation. J Clin Invest (2005) 115(4):844-8. doi: 10.1172/JCI24886 
117. Wang Y, Wu C, Yang Y, Ren Z, Lammi MJ, Guo X. Preliminary Exploration of Hsa_Circ_0032131 Levels in Peripheral Blood as a Potential Diagnostic Biomarker of Osteoarthritis. Genet Testing Mol Biomarkers (2019) 23 (10):717-21. doi: 10.1089/gtmb.2019.0036

118. Lai Z, Cao Y. Plasma miR-200c-3p, miR-100-5p, and miR-1826 Serve as Potential Diagnostic Biomarkers for Knee Osteoarthritis: Randomized Controlled Trials. Medicine (2019) 98(51):844-8. doi: 10.1097/MD.0000000000018110

119. Cao J, Han X, Qi X, Jin X, Li X. Mir-204-5p Inhibits the Occurrence and Development of Osteoarthritis by Targeting Runx2. Int J Mol Med (2018) 42 (5):2560-8. doi: 10.3892/ijmm.2018.3811

120. Huang J, Zhao L, Fan Y, Liao L, Ma PX, Xiao G, et al. The microRNAs miR204 and miR-211 Maintain Joint Homeostasis and Protect Against Osteoarthritis Progression. Nat Commun (2019) 10(1):2876. doi: 10.1038/ s41467-019-10753-5

121. Huang D, Zhao Q, Liu H, Guo Y, Xu H. PPAR- $\alpha$ Agonist WY-14643 Inhibits LPS-Induced Inflammation in Synovial Fibroblasts via NF-kB Pathway. J Mol Neurosci MN (2016) 59(4):544-53. doi: 10.1007/s12031-016-0775-y
Conflict of Interest: The authors declare that the research was conducted in the absence of any commercial or financial relationships that could be construed as a potential conflict of interest.

Publisher's Note: All claims expressed in this article are solely those of the authors and do not necessarily represent those of their affiliated organizations, or those of the publisher, the editors and the reviewers. Any product that may be evaluated in this article, or claim that may be made by its manufacturer, is not guaranteed or endorsed by the publisher.

Copyright (c) 2021 Ghafouri-Fard, Poulet, Malaise, Abak, Mahmud Hussen, Taheriazam, Taheri and Hallajnejad. This is an open-access article distributed under the terms of the Creative Commons Attribution License (CC BY). The use, distribution or reproduction in other forums is permitted, provided the original author(s) and the copyright owner(s) are credited and that the original publication in this journal is cited, in accordance with accepted academic practice. No use, distribution or reproduction is permitted which does not comply with these terms. 